DOT/FAA/AM-09/25

Office of Aerospace Medicine

Washington, DC 20591

\title{
Flight Attendant Fatigue, Part IV: Analysis of Incident Reports
}

Kali Holcomb

Katrina Avers

Lena Dobbins

Joy Banks

Lauren Blackwell

Thomas Nesthus

Civil Aerospace Medical Institute

Federal Aviation Administration

Oklahoma City, OK 73125

December 2009

Final Report 


\section{NOTICE}

This document is disseminated under the sponsorship of the U.S. Department of Transportation in the interest of information exchange. The United States Government assumes no liability for the contents thereof.

This publication and all Office of Aerospace Medicine technical reports are available in full-text from the Civil Aerospace Medical Institute's publications Web site: www.faa.gov/library/reports/medical/oamtechreports 
Technical Report Documentation Page

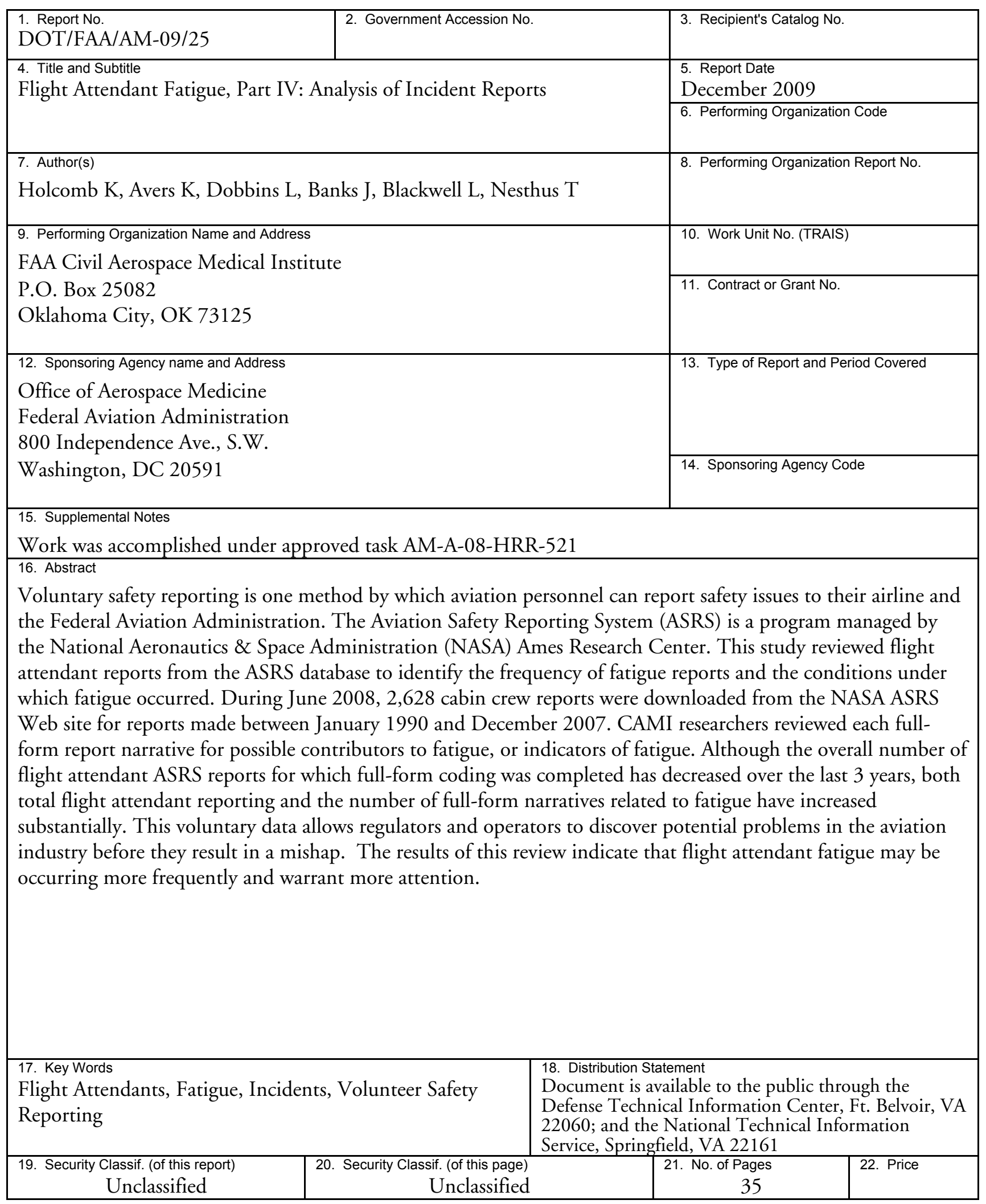

Form DOT F 1700.7 (8-72)

Reproduction of completed page authorized 



\section{ACKNOWLEDGMENTS}

Special thanks to Cristy Brown for her support and encouragement throughout this project. Another thanks to Christopher MacWhorther and Thomas Longridge of the Flight Standards Volunteer Safety Program Branch of the Federal Aviation Administration for their assistance with the Aviation Safety Action Program survey. 



\section{CONTENTS}

BACKGROUND $\ldots \ldots \ldots \ldots \ldots \ldots \ldots \ldots \ldots \ldots \ldots \ldots \ldots \ldots \ldots \ldots \ldots \ldots$

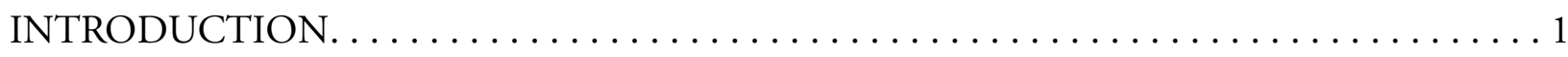

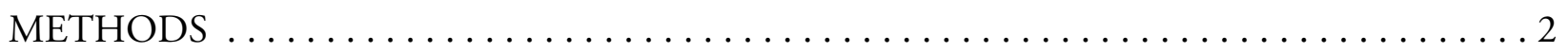

Part I: Aviation Safety Reporting System. . . . . . . . . . . . . . . . 2

Part II: Aviation Safety Action Program $\ldots \ldots \ldots \ldots \ldots \ldots \ldots \ldots \ldots \ldots \ldots \ldots \ldots \ldots \ldots \ldots \ldots$

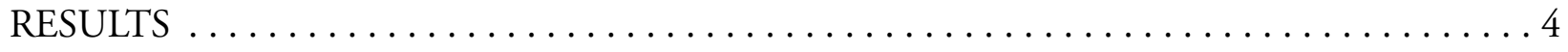

Part I: Aviation Safety Reporting System. . . . . . . . . . . . . . . . 4

Part II: Aviation Safety Action Program $\ldots \ldots \ldots \ldots \ldots \ldots \ldots \ldots \ldots \ldots \ldots$

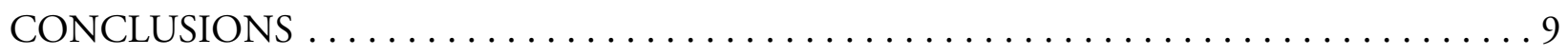

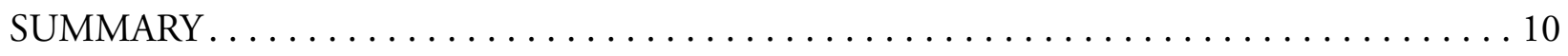

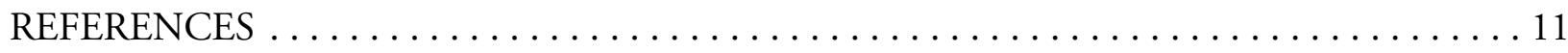

APPENDIX A: Flight attendant survey $\ldots \ldots \ldots \ldots \ldots \ldots \ldots \ldots \ldots \ldots \ldots \ldots \ldots \ldots \ldots \ldots$

APPENDIX B: Narratives relating to fatigue (source: ASRS online database) . . . . . . . . B1 



\section{Flight Attendant Fatigue, Part IV: ANALYSIS OF InCIDENT Reports}

\section{BACKGROUND}

While a great deal of research has been conducted on human circadian processes as applied to scheduling and training of flight crews, relatively little research has been accomplished among cabin crews. Performance of cabin duties is critical to both safety and security, and the literature suggests that all human performance is vulnerable to sleep loss and daily variations in physiological processes tied to underlying body-clock mechanisms. The extent of sleep loss, fatigue, and their impact upon performance of duties among the cabin crew population and within the current duty regulations is unknown.

In 2005, a Congressional directive was given to the Civil Aerospace Medical Institute (CAMI) to address issues regarding flight attendant fatigue. CAMI contracted with the National Aeronautics and Space Administration (NASA) Ames Research Center's Fatigue Countermeasures Group to conduct literature and incident report reviews and examine a range of typical flight attendant schedules to assess potential vulnerability to fatigue. Two reports were delivered by NASA and were integrated and published as a Federal Aviation Administration Office of Aerospace Medicine Technical Report (Nesthus, Schroeder, Connors, Rentmeister-Bryant, \& DeRoshia, 2007). In this report, NASA concluded that some degree of fatigue-related performance impacts were likely under the current regulations and suggested six areas of research that would facilitate understanding and government-industry decision-making. The six recommendations included: 1) a survey of field operations; 2 ) field research on the effects of fatigue; 3) a validation of models for assessing flight attendant fatigue; 4) a focused study of incident reports; 5) a review of international policies and practices; and 6) the potential benefits of training.

In 2008, Congress provided another directive for CAMI to conduct follow-on studies in each of the six recommendation areas noted in the 2007 report. To accomplish this directive, CAMI researchers developed a project plan for completing each recommendation. To facilitate support for these projects and ensure participation, CAMI researchers coordinated with representatives of vested organizations (e.g., Air Transport Association, Regional Airline Association, Coalition of Flight Attendants Association of Flight Attendants, Association of Professional Flight Attendants, Transportation Workers
Union, International Association Machinists, United Steel Workers, Delta Air Lines, and non-unionized airlines) and provided them with the opportunity to review and comment on aspects of the project plan prior to commencement.

The current report provides specific details regarding the fatigue-related content of incident reports filed by flight attendants (recommendation \# 4 - incident reports).

\section{INTRODUCTION}

Fatigue is an issue of growing concern within the aviation industry. In general, any workgroup involved in shiftwork and/or operation across time zones is likely to encounter circadian effects. This would include pilots, mechanics, flight attendants, and other crew members directly serving aircraft operations. While flight attendants may not be at the controls of the aircraft, they are responsible for the safety of the passengers and serve the pilots as their eyes and ears in the aircraft cabin. Additional safety-related duties include handling medical emergencies in an efficient and expeditious manner, as well as assessing safety threats to passengers and crew (including the increasing occurrence of passenger noncompliance and misconduct; MacDonald, Deddens, Grajewski, Whelan, $\&$ Hurrell, 2003).

Flight attendants' regularly scheduled duties include being briefed by the captain; checking first aid kits, emergency equipment, and food/beverages; greeting passengers; checking tickets; assisting with bag storage; giving safety announcements; ensuring that federal regulations (i.e., wearing seatbelts or upright seat backs) are followed; reassuring passengers; distributing materials (i.e., paperwork, pillows, blankets); assisting passengers with special needs; administering first aid; serving food and beverages, as well as documenting inventory of onboard supplies (Bureau of Labor Statistics, n.d.; Nesthus et al., 2007).

Aviation has become a 24-hour operation, which includes nights, weekends, and holidays (Bureau of Labor Statistics, n.d.). During these around-the-clock operations, physiological challenges can alter the way individuals perform their job (Rosekind, et al., 1996). One of these challenges is fatigue. In a survey of flight crews, the number of times that fatigue was cited as an issue by cabin crew members was nearly double that reported by 
cockpit crew members (Haugli, Skogstad, \& Hellesoy, 1994). Fatigue, in turn, has the potential to adversely affect flight safety (Caldwell, 2005). It is important that safety-related issues are recognized, documented, and evaluated.

Aviation personnel are able to report safety-related issues to airlines or government entities such as the FAA, without penalty, through voluntary safety reporting systems. A number of safety-reporting venues exist for aviation personnel, including the Aviation Safety Reporting System (ASRS) and the Aviation Safety Action Program (ASAP). ASRS is a national program that includes all aspects of aviation operations. ASRS is managed by the NASA Ames Research Center and enables air traffic controllers, dispatchers, pilots, mechanics, and cabin crew personnel to voluntarily and confidentially report a safety incident without punitive action (Rosenkrans, 2008; Aviation Safety Information and Analysis Sharing, n.d.). ASAP is similar to ASRS in that it is a voluntary reporting program; however, ASAP is intended for certificate-holding air carriers and major repair stations that maintain a memorandum of understanding with the FAA. In other words, ASAP has limited membership, typically workgroups within a single airline. To the good, this results in airlines taking actions to correct their own problems. However, integration across airlines is necessary to ensure that problems of national scope are not treated as unique or isolated issues. Data from ASAP are not consolidated into one central database but are held by the airlines. The Aviation Safety Information Analysis and Sharing (ASIAS) now compiles or accesses many aviation safety databases, including participating airlines' ASAP programs, though this has not yet extended to flight attendant programs. Thus, any examination of safety issues reported by flight attendants is limited to studies of the ASRS database.

The purpose of this study was to utilize existing safety reports to identify commonly cited safety issues and conditions associated with fatigue-related reports for flight attendants. Additional information was requested from Event Review Committee (ERC) members representing the flight attendant ASAP programs to gain insight into fatigue-related issues identified within airline programs.

\section{METHODS}

\section{Part I: Aviation Safety Reporting System}

The NASA ASRS public Web site was queried to examine existing flight attendant safety reports (National Aeronautics and Space Administration Aviation Safety Reporting System, n.d.). The public Web site consists of full-form records entered into a permanent Web site by NASA. Full-form records are a subset of reports received by ASRS. Historically, less than $20 \%$ of all reports have been entered into the database (ASIAS, n.d). However, the inclusion rate for flight attendants has been greater, averaging 36\% from 1997 to 2007 (C.R. Drew, personal communication, November 10, 2009).

The query was restricted to reports submitted between January 1990 and December 2007. The query resulted in 2,628 reports.

NASA analyzed the reports for a wide variety of safety issues. For the purposes of this study, CAMI researchers then reviewed each full-form report narrative to identify common themes. Using this review process, we identified a number of categories that could be considered as either 1) possible contributors to fatigue, or 2) indicators of fatigue. To confirm the relevance of each identified category, a comparison to an existing flight attendant fatigue literature review (Nesthus et al., 2007) was conducted. Every identified category was also cited in the literature as a possible contributor to fatigue and was therefore retained for further analysis in the current report. See Table 1 for descriptions of the identified categories and operational definitions. Once the categories were identified and confirmed, all of the report narratives were reviewed and analyzed using those categories. Along with those categories, a few of the many NASA ASRS categories (passenger illness and aircraft equipment problems [critical and less severe]) were used in the analyses for this report.

\section{Part II: Aviation Safety Action Program}

To gather additional information observed by ERC members of the flight attendant ASAP programs, a survey was developed. Surveys were distributed via E-Mail to 23 participants for airlines that had a flight attendant program for at least 6 months prior to the March 2009 distribution. The participants consisted of an FAA representative, company representative, labor representative, and the principal operations inspector for each airline. The survey asked the participants for feedback regarding their ASAP program and more specifically about fatiguerelated reports they had received. E-Mails sent to each committee member contained a link to the survey that was created through the SNAP Surveys ${ }^{\circledR}$ software. The survey was approximately 20 questions in length and consisted of multiple-choice options, as well as openitem response options (Appendix A). Ten surveys were returned, but only seven respondents met the criteria for inclusion (i.e., had at least one report submitted to the program that involved fatigue/scheduling issues). 
Table 1. Operational Definitions of Identified Categories.

\begin{tabular}{|c|c|}
\hline \multicolumn{2}{|r|}{ Possible Contributors to Fatigue } \\
\hline Crew Coordination/ Communication & $\begin{array}{l}\text { Disagreements or lack of communication with any combination of flight } \\
\text { attendant(s), flight } \operatorname{crew}(\mathrm{s}) \text {, or gate agent(s) }\end{array}$ \\
\hline Crew Illness/Injury & Flight attendant or flight crew becomes sick or injured during the flight \\
\hline \multicolumn{2}{|l|}{ Passenger Misconduct } \\
\hline Alcohol & Passenger(s) having excessive amounts or unapproved alcohol \\
\hline Bomb/Hijack Threat & $\begin{array}{l}\text { Verbal/written communication was heard/seen by a flight attendant } \\
\text { regarding a bomb on board, or threats of overtaking the cockpit }\end{array}$ \\
\hline Disruptive/Rude & $\begin{array}{l}\text { Passenger(s) were disruptive to the duties of the flight attendant, rude to } \\
\text { flight attendant (both verbally and/or physically); passengers fighting or just } \\
\text { causing havoc }\end{array}$ \\
\hline Drug/Medicine & Passengers had signs of illegal drug use, overmedicated, or under-medicated \\
\hline Electronic Device & $\begin{array}{l}\text { Passengers refused to turn off/discontinue use of an electronic device (cell } \\
\text { phone, laptop) }\end{array}$ \\
\hline Luggage/Baggage Storage & $\begin{array}{l}\text { Luggage/baggage was not properly stowed, was oversized, or required flight } \\
\text { attendant assistance }\end{array}$ \\
\hline Pets & Passengers refusing to properly store their pets during flight \\
\hline Smoking & Passengers caught/suspected of smoking on board the aircraft \\
\hline Unauthorized Passenger & Individual was on board the aircraft without the appropriate paperwork \\
\hline Other & $\begin{array}{l}\text { Something that caused a problem or was an issue for the flight attendant that } \\
\text { was not previously identified in the other categories }\end{array}$ \\
\hline \multicolumn{2}{|r|}{ Indicators of fatigue } \\
\hline Crew Rest Facility & $\begin{array}{l}\text { Less than adequate environment for a rest facility, too much or lack of noise, } \\
\text { light, and/or turbulence disrupting rest }\end{array}$ \\
\hline Duty Time & Hours during a shift \\
\hline Fatigue & Tired, fatigued, exhausted, worn out, etc \\
\hline Lack of Sleep/Rest & Hours of sleep or rest \\
\hline No/Missing Break/Meal & $\begin{array}{l}\text { Flight attendant missed a break (including meal breaks) or one was not } \\
\text { scheduled during or between flights }\end{array}$ \\
\hline Scheduling & $\begin{array}{l}\text { Number of days worked without a day off and/or working night shifts or } \\
\text { early morning }\end{array}$ \\
\hline
\end{tabular}




\section{RESULTS}

\section{Part I: Aviation Safety ReportingSystem}

Overall Cabin Crew Reports. A review of the number of flight attendant reports filed between 1990 and 2007 revealed substantial variation in the number of reports filed each year and in the rate at which reports were full-form coded and available in the public database (see Table 2). ASRS did not offer cabin crew-specific reporting prior to 1995 but received and processed some reports. Reporting decreased after 2001 (perhaps reflecting the post-9/11 reduction in total industry flights) but increased sharply in 2006 and 2007. Full-form coding rates have not kept pace with reporting rates, which limits the representativeness of the reports available for content analysis.

Contributing Factor Narratives. Content analysis of ASRS narratives revealed that a number of safety-related issues could also be considered contributors to fatigue. In other words, there were numerous in-flight issues that probably created extra work and stress for flight attendants. For example, passenger misconduct was reported in more than one-third (36.1\%) of the narratives. Of those, the most frequently occurring reports $(80 \%)$ involved passengers that were disruptive and/or rude. The second highest reported issue involved excessive or unapproved use of

Table 2. Number of ASRS Reports Filed by Cabin Crew. ${ }^{a}$

\begin{tabular}{|l|c|c|c|}
\hline Year & $\begin{array}{c}\text { Reports } \\
\text { Received }^{\text {b }}\end{array}$ & $\begin{array}{c}\text { Full-form } \\
\text { Reports }\end{array}$ & $\begin{array}{c}\text { Full-form } \\
\text { Percentage }\end{array}$ \\
\hline 1990 & unavailable & 2 & \\
\hline 1991 & unavailable & 6 & \\
\hline 1992 & unavailable & 2 & \\
\hline 1993 & unavailable & 6 & \\
\hline 1994 & unavailable & 3 & \\
\hline 1995 & unavailable & 9 & \\
\hline 1996 & unavailable & 23 & \\
\hline 1997 & 50 & 59 & $118.0 \%$ \\
\hline 1998 & 622 & 387 & $62.2 \%$ \\
\hline 1999 & 737 & 551 & $74.8 \%$ \\
\hline 2000 & 896 & 440 & $49.1 \%$ \\
\hline 2001 & 754 & 267 & $35.4 \%$ \\
\hline 2002 & 505 & 244 & $48.3 \%$ \\
\hline 2003 & 437 & 245 & $56.0 \%$ \\
\hline 2004 & 489 & 139 & $28.4 \%$ \\
\hline 2005 & 585 & 68 & $11.6 \%$ \\
\hline 2006 & 1,093 & 115 & $10.5 \%$ \\
\hline 2007 & 1,035 & 62 & $5.9 \%$ \\
\hline Total & $\mathbf{7 , 2 0 3}$ & $\mathbf{2 , 6 2 8}$ & $\mathbf{3 6 . 1 \%}$ \\
\hline
\end{tabular}

a "...the full form counts are sorted by Item date (incident date), not received date, so there is the possibility of year cross over" (Drew, personal communication, November 10, 2009).

${ }^{\mathrm{b}}$ Reports received were not recorded prior to 1997 ; therefore, these data are unavailable. alcohol (32\%). All other types of passenger misconduct were reported less frequently (Figure 1).

Illness or injury to passengers and/or crew members was identified as another issue that could contribute to flight attendant fatigue; $22.3 \%$ of the narratives involved some type of injury or illness of passenger(s) or crew. Passenger illness was reported in $46.8 \%$ of those narratives (Figure 2).

Flight attendants are also exposed to problems that occur both outside and inside the aircraft cabin. Thirtyfive percent of the narratives had an aircraft equipment problem that was rated as either critical $(27.7 \%)$ or less severe $(7.5 \%)$. When the problem occurred outside of the cabin, flight attendants were sometimes required to prepare the aircraft for an emergency, diversion, or unscheduled landing. In these instances, as well as during normal operations, crew coordination and communication are essential. Crew coordination/communication issues were reported in a little more than $6 \%$ of the narratives.

Cabin Crew Fatigue Reports. Of the 2,628 narratives analyzed, $62(2.4 \%)$ reports cited some type of flight attendant fatigue issue (see Appendix B). Although the ASRS full-form processing strategy was not uniformly applied and cannot be generalized, the trend in the ASRS database suggests the percentage of full-form reports discussing fatigue is increasing. See Table 3 for the number and corresponding percentage of fatigue-related reports receiving full-form processing each year since 1990 .

An examination of the fatigue-related narratives revealed that duty time $(51.6 \%)$ and scheduling (48.4\%) concerns occurred most frequently. Figure 3 shows the relative percentage of occurrence for the issues identified as fatigue-related factors in the cabin crew narratives.

A number of the fatigue-related reports $(\mathrm{N}=41)$ specified the approximate time of day for the incident. The late evening/night (1801-2400) and morning (0601-1200) timeframes were the most common times for an event resulting in a fatigue-related narrative to occur $(31.7 \%$ and $29.3 \%$, respectively; Figure 4).

A co-occurrence examination was conducted of the potential fatigue contributors with the fatigue-related incidents. The results revealed that passenger misconduct was discussed in $8.1 \%$ of the fatigue-related narratives. Of these, passenger disruptiveness and/or rudeness were identified $100 \%$ of the time. One narrative included both alcohol and drug complaints (Figure 5).

An examination of crew illness/injury and its cooccurrence with fatigue-related narratives indicates that crew illness/injury was discussed almost $10 \%$ more frequently in fatigue-related reports than in other full-form narratives (Figure 6). 


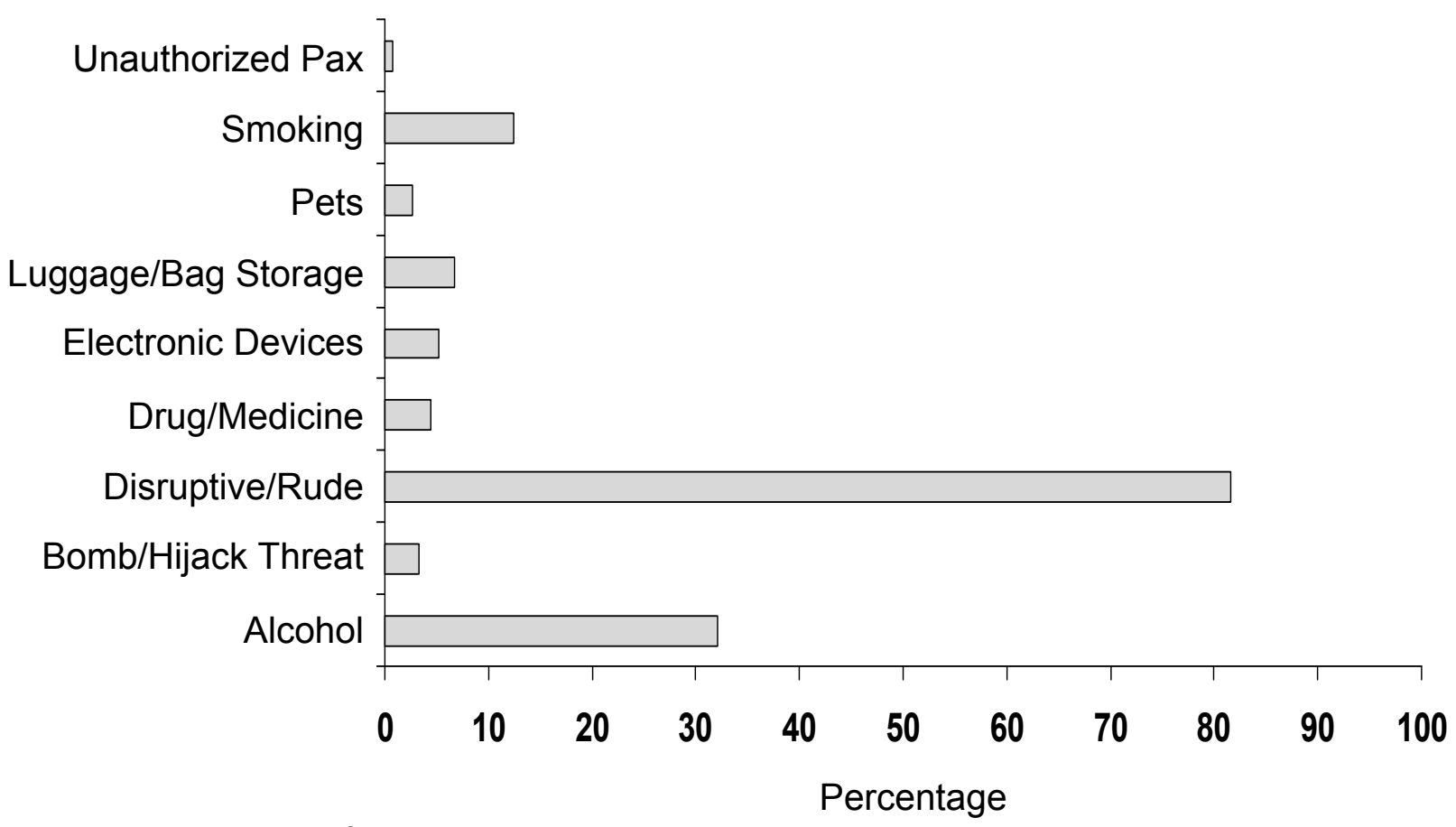

Figure 1. Percentage of passenger misconduct reports by misconduct category

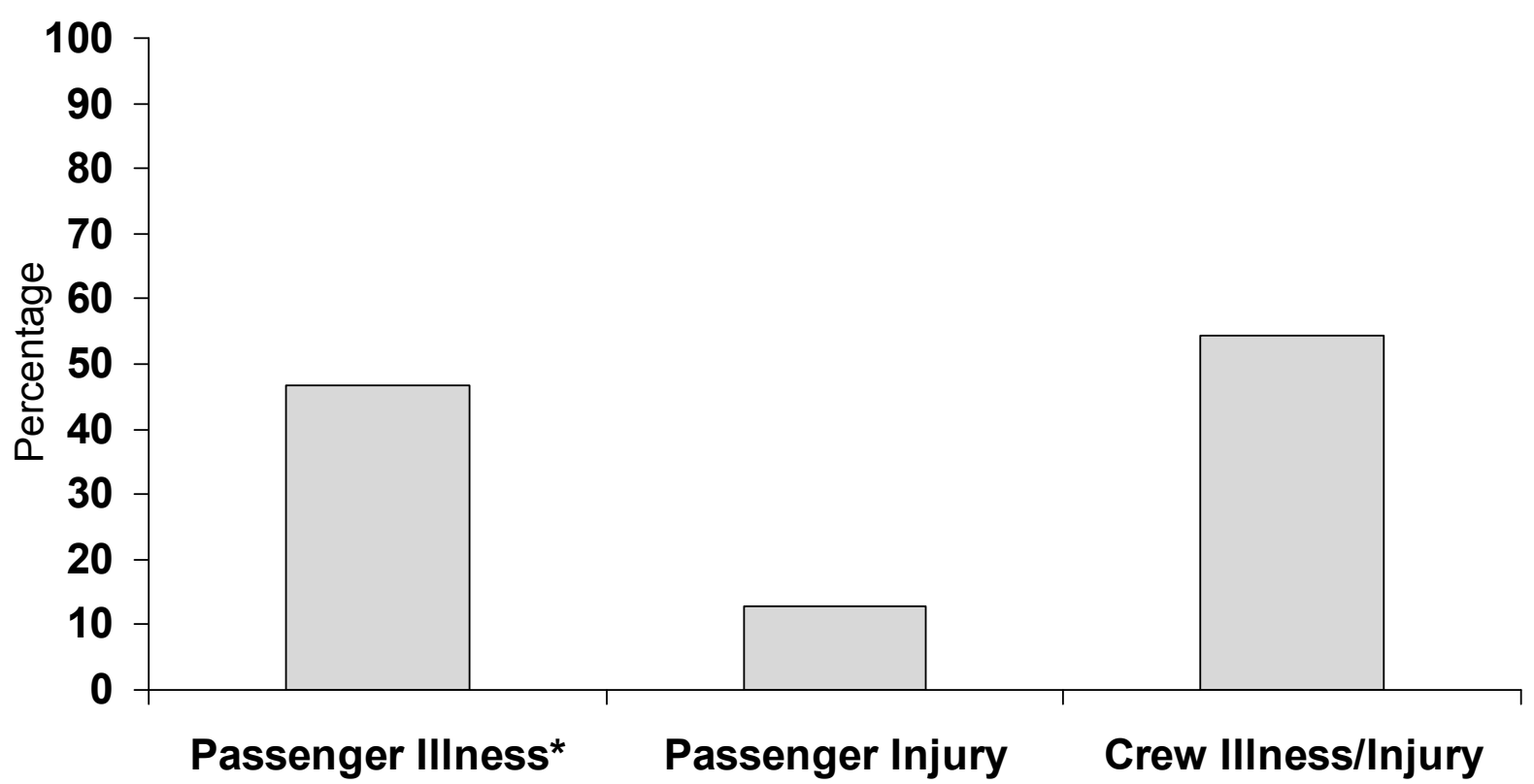

*Note: Prior to 1998, passenger illness on a flight was not documented in the database.

Figure 2. Percentage of illness and injury in cabin crew reports. 
Table 3. Number and Corresponding Percentage of Cabin Crew Fatigue Reports by Year.

\begin{tabular}{|c|c|c|}
\hline Year & $\begin{array}{c}\text { Number of full- } \\
\text { form reports } \\
\text { discussing fatigue }\end{array}$ & $\begin{array}{c}\text { Percentage of full- } \\
\text { form reports } \\
\text { discussing fatigue }\end{array}$ \\
\hline 1990 & 0 & $0.0 \%$ \\
\hline 1991 & 0 & $0.0 \%$ \\
\hline 1992 & 1 & $50.0 \%$ \\
\hline 1993 & 0 & $0.0 \%$ \\
\hline 1994 & 0 & $0.0 \%$ \\
\hline 1995 & 1 & $11.1 \%$ \\
\hline 1996 & 1 & $4.3 \%$ \\
\hline 1997 & 2 & $3.4 \%$ \\
\hline 1998 & 2 & $0.5 \%$ \\
\hline 1999 & 6 & $1.1 \%$ \\
\hline 2000 & 6 & $1.4 \%$ \\
\hline 2001 & 3 & $1.1 \%$ \\
\hline 2002 & 0 & $0.0 \%$ \\
\hline 2003 & 5 & $2.0 \%$ \\
\hline 2004 & 3 & $2.2 \%$ \\
\hline 2005 & 11 & $16.2 \%$ \\
\hline 2006 & 11 & $9.6 \%$ \\
\hline 2007 & 10 & $16.1 \%$ \\
\hline Total & 62 & $2.4 \%$ \\
\hline Perchtan & & \\
\hline
\end{tabular}

${ }^{a}$ Percentage of full-form reports discussing fatigue calculated by dividing the total number of full form reports available in ASRS database.

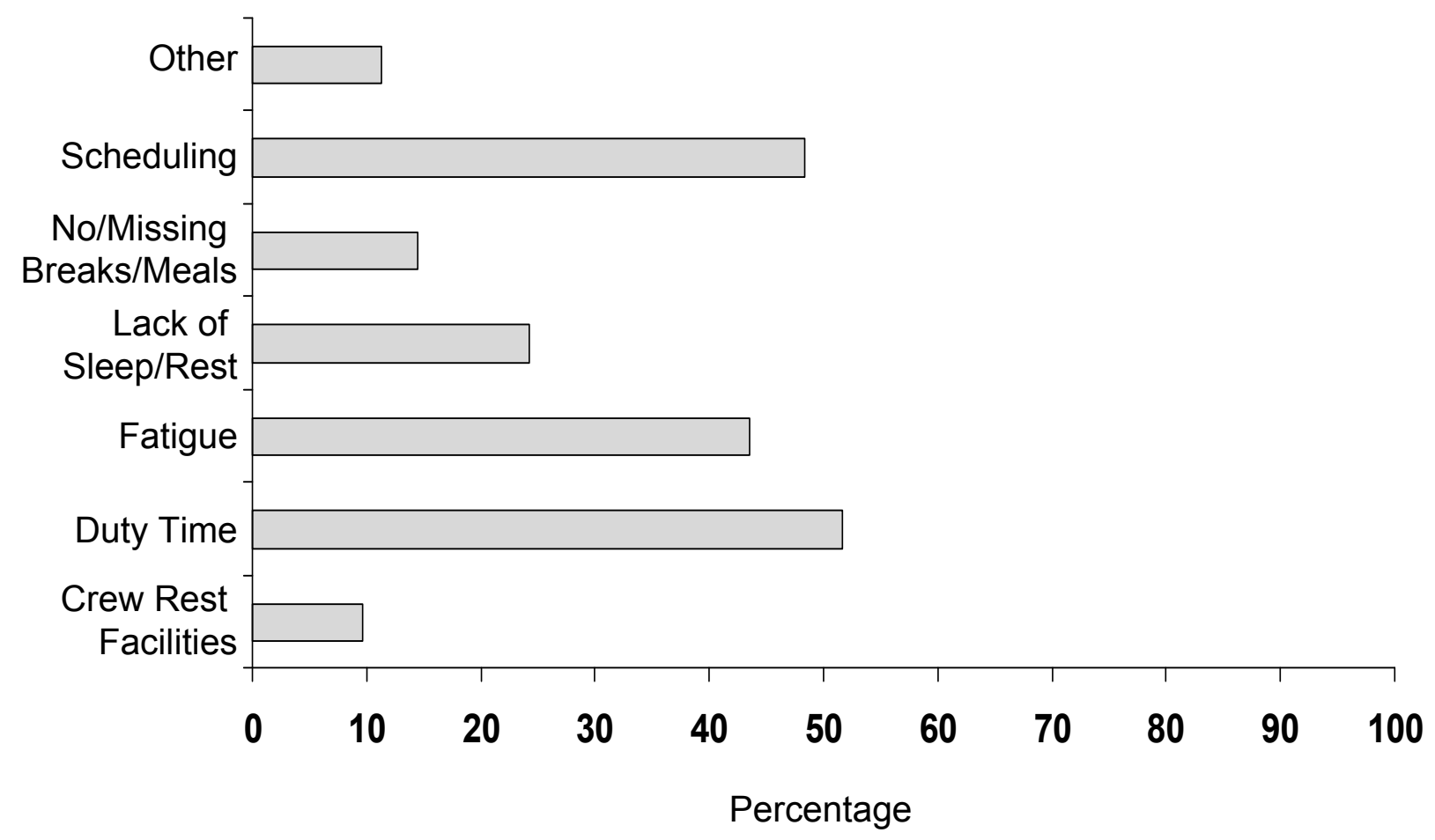

Figure 3. Percentage of fatigue factors discussed in narratives. 


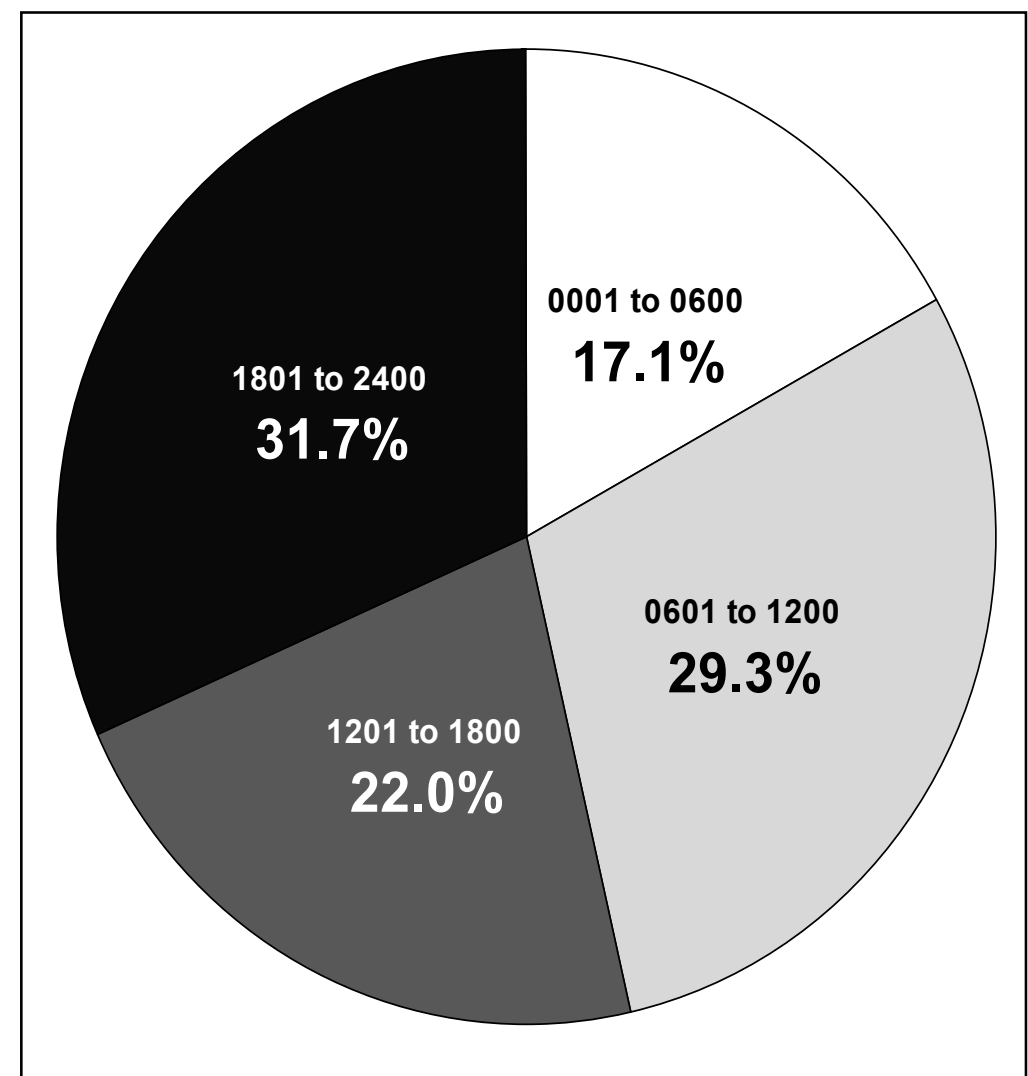

Figure 4. Percentage of full-form fatigue reports by incident time of day.

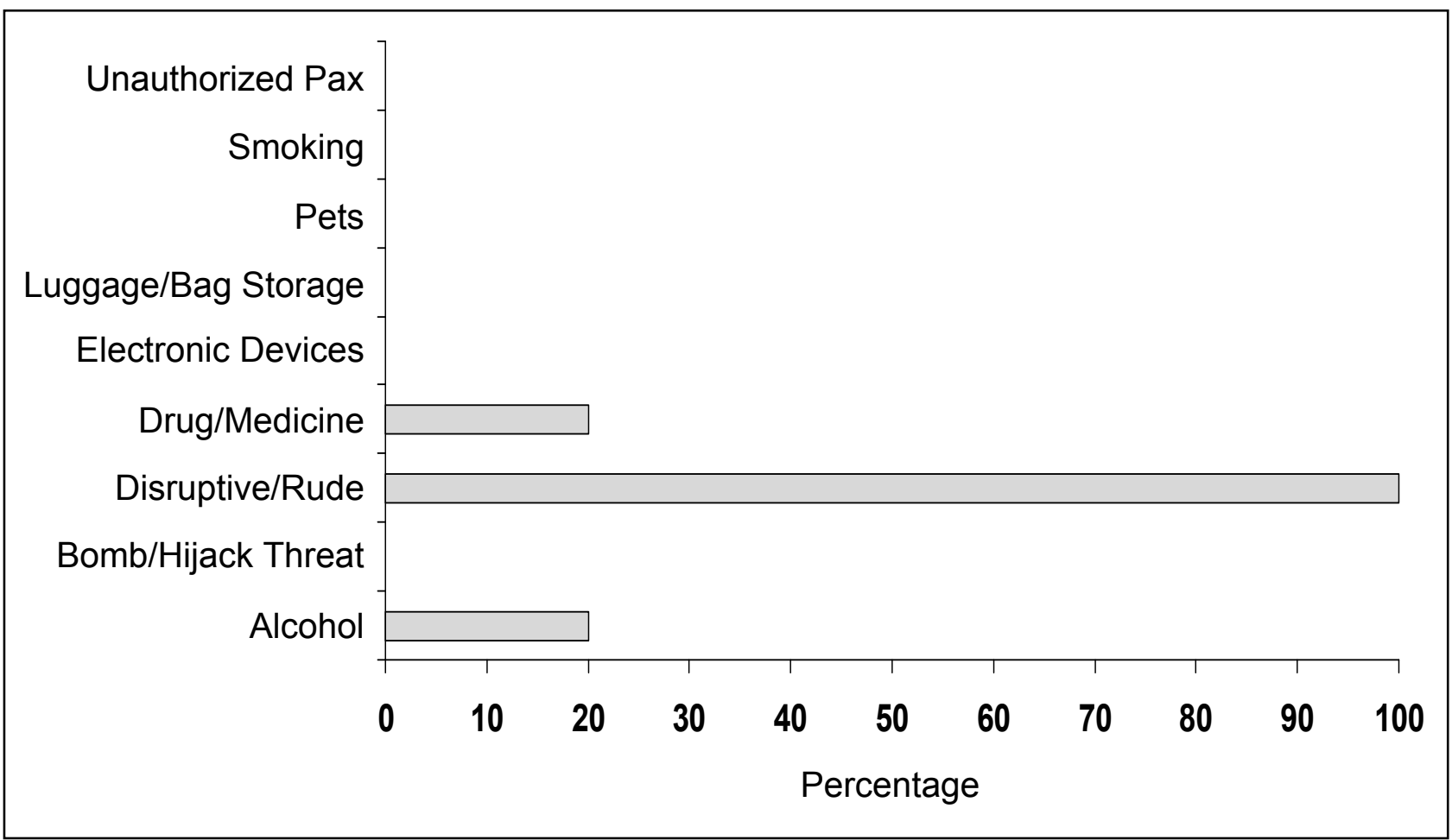

Figure 5. Percentage of passenger misconduct categories in fatigue-related reports. 


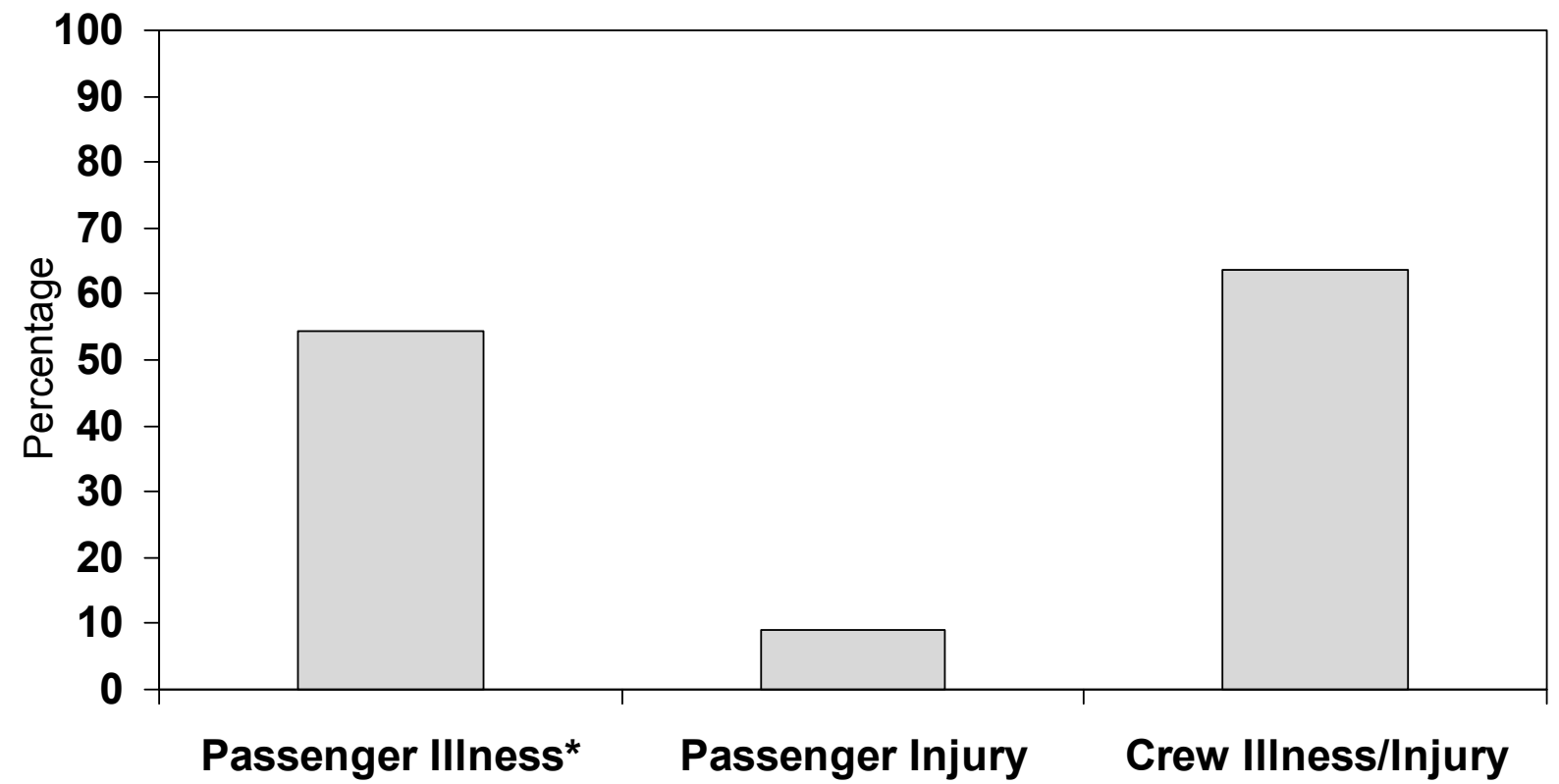

*Note: Prior to 1998, passenger illness on a flight was not documented in the database. Figure 6. Percentage of illness and injury of those reports involving fatigue.

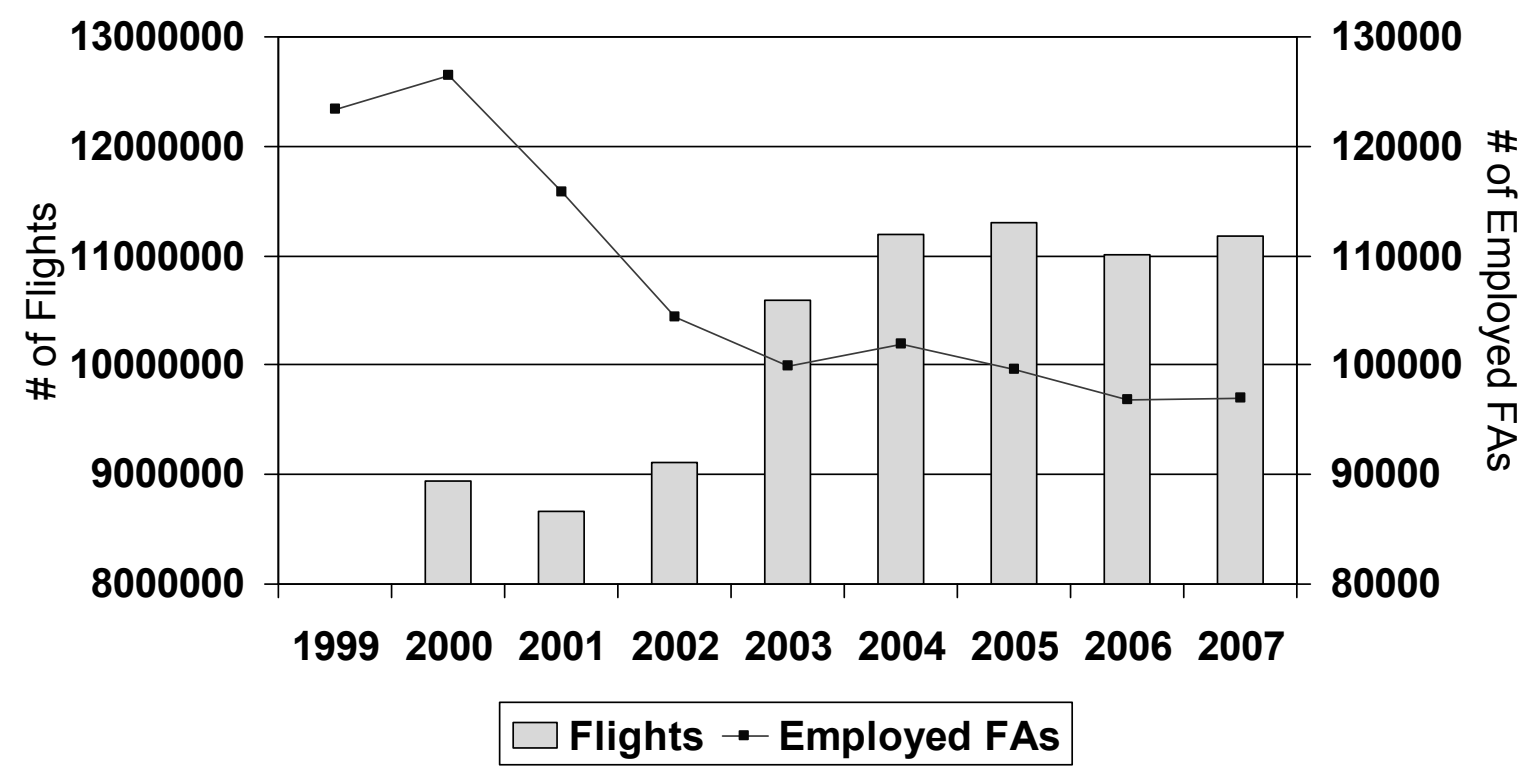

Figure 7. Number of flights and number of employed flight attendants as reported by the Bureau of Transportation Statistics (2008 \& n.d.). 
Of the narratives involving fatigue, $24.2 \%$ discussed an aircraft equipment problem that was either critical $(12.9 \%)$ or less severe $(11.3 \%)$. Percentages of critical aircraft problems were less than those among other full-form narratives. In contrast, percentages of less severe equipment problems were discussed much more frequently (nearly double) in fatigue-related narratives than among other full-form narratives. Similarly, crew coordination/communication issues were discussed more frequently in fatigue-related narratives than among other full-form narratives $(8.1 \%$ versus $2 \%)$.

\section{Part II: Aviation Safety Action Program}

With such a small sample size and low return rate of the ASAP survey responses, meaningful analyses could not be conducted. Confidentiality could not be assured, and the results could not be generalized to the population. However, qualitative responses to the open-item questions did reveal some common issues and recommendations for more effective education. Specifically, several respondents discussed the need to provide education concerning health issues and effects of fatigue to the flight attendant community.

\section{CONCLUSIONS}

Although the overall number of flight attendant ASRS reports for which full-form coding was completed has decreased over the last 3 years, both total flight attendant reporting and the number of full-form narratives related to fatigue have increased substantially. From 1990 to 2004, the number of fatigue-related full-form reports per year averaged 2.4. In the past 3 years, the number of fatiguerelated full-form reports per year averaged 10.5. Without access to the narratives for which full-form coding was not completed, we cannot determine whether the underlying fatigue-related reporting rate has changed. However, assuming full-form reports are representative of all submitted reports, this suggests an increase in the typical number of fatigue-related incidents. This is consistent with growing concerns voiced by the flight attendants and with results found in recent survey results examining flight attendant fatigue (Avers, King, et al., 2009).

We must also consider whether documenting a change in reporting or in underlying fatigue-related events is necessary to being concerned about fatigue among flight attendants. Voluntary safety reports are important to aviation safety because they can identify issues and problems of which the airline, industry, and government would otherwise be unaware. From that perspective, every report is important, and most we would prefer that events not occur at all. However, the reports provide only one perspective on the events and do not include other objective data concerning an event (except among ASAP reports examined within individual airlines). Statistical analysis of voluntary reports introduces other limitations - a report database will include only those events people cared enough to report, potentially under-or over-representing events in unknown ways. So, conclusions from statistical analyses must be limited to trends in reporting. For the present ASRS analysis, the varying rate of full-form processing was especially limiting - we can only discuss the extent to which fatigue or potentially-contributing issues are represented in full-form narratives. Nonetheless, these narratives are often quite rich in their discussion of individual events and can be treated as illustrations of the issues flight attendants encounter during their duties. The content of the reports must be compared or contrasted with the data collected in surveys (Avers, King, et al., 2009) and field studies among flight attendants. For example, approximately $50 \%$ of the fatigue-related narratives involved concerns associated with scheduling and/or duty time issues - a finding that is largely consistent with recent survey results examining flight attendant fatigue (Avers, King, et al., 2009).

Comparison of overall ASRS reporting rates to changes in flight attendant reporting may offer an additional insight. An examination of Bureau of Transportation Statistics reports $(2008$, n.d.) indicates that the number of flights has increased, while the number of employed flight attendants has decreased markedly over the last several years (Figure 7). Similar trends were reported in a study of Japanese flight attendant fatigue (Ono, Watanabe, Kaneko, Matsumoto, \& Miyao, 1991). The increase in ASRS flight attendant reporting in 2006 and 2007 (double that received in each of the previous 4 years) is out of step with flight attendant employment. There are numerous other factors that could account for reporting changes, but the co-occurrence of increased reporting, increases in flight operations, and reductions in the number of flight attendants should be further examined.

The scheduling and/or duty time concerns cited in ASRS narratives are likely tied to physiological processes known to impact humans supporting 24/7 operations. Flight attendants travel nationally and internationally across multiple time zones in a manner that is likely to disrupt their normal circadian rhythms (Nesthus et al., 2007). The impact of time zone changes on aviation personnel is well documented. Task performance has been found to degrade significantly during shiftwork coupled with time zone changes (Caldwell, 2005). Caldwell also found that incident reports were more frequent and simulator performance less effective among pilots during the earlymorning hours. Similarly, fatigue narratives analyzed in the present ASRS study largely involved flights between 0600 and noon. Although the times provided in the ASRS reports were "local times" associated with the event, the 
time reported may not have been the same as the biological clock-time for the flight attendant.

In addition to time zone changes, long duty days have also been reported to impact fatigue. Avers, King, and associates (2009) found that length of duty day was one of the most frequently reported fatigue factors among flight attendants. The narratives analyzed in the present study offer illustrations of this issue.

In a study conducted by Brown (2009), pilots and flight attendants were asked the following question, "Have the effects of fatigue due to jet lag, short layovers, long duty days, or long haul flights, ever affected your ability to perform your duties safely?" A large portion of that study's participants responded that it "would greatly affect safety." (p. 44).

Lack of sleep/rest was cited as another fatigue-related factor in $25 \%$ of the narratives. Rosekind et al. (1996) concluded that "Sleep loss creates sleepiness, which can be associated with decrements in vigilance, reaction time, memory, psychomotor coordination, information processing, and decision making (e.g., fixation on certain aspects of a situation to the neglect of other information). With increasing sleepiness, individuals demonstrate poorer performance despite increased effort ...” (p. 158).

This report examined the fatigue-related issues reported by flight attendants to the ASRS and ASAP programs. Various types of physical and mental fatigue were discussed in narratives, and most can be linked in some way to underlying human physiology. Effective education and training may combat mental and physiological fatigue. Avers, Hauck, Blackwell, and Nesthus (2009) reviewed fatigue training programs and their beneficial effects on personnel. They identified many critical components of a comprehensive program and concluded that a flight attendant fatigue training program would be a "beneficial method for managing and mitigating the effects of fatigue." Additionally, the review of ASAP program comments provided valuable insight into the benefits and potential recommendations for flight attendant fatigue countermeasures. Educating flight attendants was a central recommendation, as well as reducing the maximum number of flight duty hours for flight attendants. Caldwell (2005) stated that "...fatiguemanagement strategy is crucial for fighting the acute sleep loss/sleep debt, the sustained periods of wakefulness, and the circadian factors that are primary contributors to fatigue-related flight mishaps." (p. 90). Nevertheless, one of the problems in developing fatigue mitigation strategies is that everyone's physiology (including circadian rhythms and tolerance to sleep loss) is different, and creating an allencompassing fatigue training program that fits everyone's needs is difficult (Caldwell, 2005; Rosekind et al., 1996).

Another suggested contributor to fatigue is the mental demand placed on flight attendants (MacDonald et al.,
2003). Narratives often discussed crew coordination/ communication and circumstances involving passengers, sources of increased mental demand, or workload. Passengers that caused disruption or were under the influence of alcohol were highlighted in many narratives. Most of the communication/coordination complaints described in the full-form narratives involved communication between a flight attendant and the cockpit crew. Coordination/ communication between pilots and flight attendants has been highlighted by Chute $\&$ Wiener (1995), suggesting a disjunction of culture between the two work groups. These differences have resulted in problems in communication of safety-related information (Chute \& Wiener, 1996). The narratives suggest that miscommunication and/or lack of communication between pilots and flight attendants can add additional stress to the cabin crew, working to exacerbate, rather than reduce, fatigue among both groups.

Data represented in the ASRS reports are submitted by flight attendants, so not every report was linked to fatigue or contributors of fatigue. For instance, the mental demand for a passenger who is caught smoking on the aircraft, who then apologizes and behaves for the rest of the flight, is much different than the demand imposed by a passenger who continues to smoke for the rest of the flight.

\section{SUMMARY}

ASRS and ASAP data are not completely representative of the issues that are faced by the flight attendant population; however, there is no single, representative database of flight attendant issues. First, these programs are voluntary, and the data are not required to be reported; therefore, not every occurrence of the issues we examined may be captured in their entirety, and some issues may not have been addressed at all. Second, the information usually reported in these programs is related to critical events, issues, or problems, and are generally not positive. The information reported is based upon experiences of the cabin crewmembers and may be influenced by their perspective (Aviation Safety Information and Analysis Sharing, n.d.). However, analyses of voluntary reporting program data can uncover potential problems and provide evidence and recommendations for developing effective methods to improve the issues before they become a serious hazard. The results of this review and analysis indicate that flight attendants report fatigue and potentially contributing factors somewhat frequently. The specific issues they discuss should be treated as illustrations of the issues identified in surveys and field studies of flight attendant fatigue. Themes in the narratives analyzed echo issues raised in the survey (Avers, King, et al., 2009) and provide support for its recommendations for science-based scheduling and countermeasure training. 


\section{REFERENCES}

Aviation safety information analysis and sharing. Aviation Safety Reporting System (ASRS). (n.d.). Retrieved January 22, 2009 from www.asias.faa.gov/pls/ portal/docs/PAGE/ASIAS_PAGES/LEARN_ ABOUTS/ASRS_LA.html.

Avers, K., King, S., Nesthus, T., Thomas, S., \& Banks, J. (2009). Flight attendant fatigue, Part I: National duty, rest, and fatigue survey. (Technical Report DOT/FAA/AM-09/24). Washington, DC: Federal Aviation Administration, Office of Aerospace Medicine.

Avers, K., Hauck, E., Blackwell, L., \& Nesthus, T. (2009). Flight attendant fatigue, Part VI: Fatigue countermeasures training and potential benefits. (Technical Report DOT/FAA/AM-09/20). Washington, DC: Federal Aviation Administration, Office of Aerospace Medicine.

Brown, L. (2009). The efficacy of flight attendant/pilot communications in a post 9/11 environment: Viewed from both sides of the fortress door. Unpublished draft manuscript.

Bureau of Labor Statistics (n.d.) Occupational outlook handbook, 2008-09 edition: Flight attendant. Retrieved August 11, 2009 from www.bls.gov/oco/ ocos171.htm.

Bureau of Transportation Statistics (2008). National transportation statistics. Retrieved July 21, 2009 from www.bts.gov/.

Bureau of Transportation Statistics (n.d). Retrieved July 21, 2009 from www.transtats.bts.gov/Data_Elements.aspx?Data $=2$.

Caldwell, J. (2005). Fatigue in aviation. Travel Medicine and Infectious Disease, 3, 85-96.

Chute, R. \& Wiener, E. (1995). Cockpit-cabin communication: I. A tale of two cultures. The International Journal of Aviation Psychology, 5(3), 257-276.
Chute, R. \& Wiener, E. (1996). Cockpit-cabin communication: II. Shall we tell the pilots? The International Journal of Aviation Psychology, 6(3), 211-231.

Federal Aviation Administration (2002). Advisory circular number 120-66B: Aviation Safety Action Program (ASAP). Retrieved July 21, 2009 from rgl.faa.gov/ Regulatory_and_Guidance_Library/rgAdvisoryCircular.nsf/0/61c319d7a04907a886256c79006 48358/\$FILE/AC120-66B.pdf.

Haugli, L. Skogstad, A., \& Hellesoy, O. (1994). Health, sleep, and mood perceptions reported by airline crews flying short and long hauls. Aviation, Space, and Environmental Medicine, 65(1), 27-34.

MacDonald, L., Deddens, J., Grajewski, B., Whelan, E., \& Hurrell, J. (2003). Job stress among female flight attendants. Journal of Environmental Medicine, 45 (7), 703-714.

National Aeronautics and Space Administration (NASA) Aviation Safety Reporting System (ASRS). Retrieved in 2009 from asrs.arc.nasa.gov/.

Nesthus, T., Schroeder, D., Connors, M., RentmeisterBryant, H., \& DeRoshia, C. (2007). Flight attendant fatigue. (Technical Report DOT/FAA/AM-07/21). Washington, DC: Federal Aviation Administration, Office of Aerospace Medicine.

Ono, Y., Watanabe, S., Kaneko, S., Matsumoto, K., \& Miyao, M. (1991). Working hours and fatigue of Japanese flight attendants. Journal of Human Ergology, 20(2), 155-164.

Rosekind, M., Gander, P., Gregory, K., Smith, R., Miller, D., Oyung, R, et al. (1996). Managing fatigue in operational settings 1: Physiological consideration and countermeasures. Behavioral Medicine, 21, 157-165.

Rosenkrans, W. (2008, January). Speaking up. Aerosafety World, 34-39. 



\section{APPENDIX A}

1. When did you start serving on the ASAP ERC for Flight Attendant reporting?

2. What type of air carrier do you oversee?

a. Network (Operates a significant portion of flights using at last one hub where connections are made for flights on spoke systems [e.g. American, United, Continental])

b. Low Cost (Industry recognizes as operating under a low-cost business model, with lower infrastructure costs and higher rates of productivity [e.g., Southwest, US Airways, Jetblue])

c. Regional (Provides service from small cities, using primarily regional jets to support the network carriers hub and spoke systems [e.g., Sky West, American Eagle, Express jet])

d. Other Carrier (Other airline not listed above that operates within a specific niche market [e.g., Hawaiian Airlines])

3. When did your air carrier become involved with the Flight Attendant ASAP program?

4. On average, how many Flight Attendants are employed by your air carrier?

5. How many Flight Attendant ASAP events have been submitted for your air carrier? (Required)

6. What percentage of Flight Attendant ASAP events are also reported to NASA's Aviation Safety Reporting System (ASRS)?

7. Have you discussed Flight Attendant fatigue/scheduling issues within your ERC?

8. What percentage of Flight Attendant ASAP events have involved scheduling/fatigue issues? (Required)

9. What specific issues were involved in fatigue-related ASAP events? (Mark all that apply)
a. Fatigue
b. Scheduling
c. Length of duty time
d. Other

10. When did fatigue-related ASAP events most frequently occur?
a. 06:00-09:59
b. $10: 00-13: 59$
c. $14: 00-17: 59$
d. $18: 00-21: 59$
e. 22:00-01:59
f. 02:00-05:59

11. When did fatigue-related ASAP events most frequently occur in the duty day?
a. Early in the duty day
b. Middle of the duty day
c. Late into the duty day

12. Did fatigue-related ASAP events typically occur during a single leg or multiple leg duty day?
a. Single leg
b. Multiple leg

13. When did fatigue-related ASAP events typically occur?
a. Boarding
b. Deplaning
c. During service
d. Safety-related duties
e. Other

14. What percentage of fatigue-related ASAP events resulted in a severe outcome?

15. What percentage of fatigue-related ASAP events resulted in injury(s) to...
a. passengers
b. flight attendants
c. other crew members

16. What percentage of fatigue-related ASAP events resulted in an evacuation?

17. What issues have you identified as common precursors to fatigue-related ASAP events?

18. Based on your experience, do you have any recommendations for minimizing or reducing fatigue-related ASAP events?

19. Any additional information regarding fatigue-related events 



\section{APPENDIX B}

Report numbers and narratives of the reports are categorized as fatigue. Narratives came from the National Aeronautics and Space Administration Aviation Safety Reporting System's online database. (Note: Narrative formats were changed for legibility.)

230404

Narrative: On Dec/Sun/92, I was a flight attendant on an air carrier flight from Charlotte to Raleigh Durham. Due to the weather conditions, freezing rain and low temperatures, aircraft deicing was being done. We were experiencing $31 / 2$ to 4 hour delays to be deiced. At approximately PM45, we finally took our turn on the deicing pad. It is my understanding that the pilots and ground crew had communication with one another and that the procedure had been completed. We then got into position for the active runway. Shortly after that the captain made the announcement for the flight attendants to prepare for departure. A passenger informed me that the left wing had not been deiced. I immediately telephoned the captain and we were able to leave the runway and avoided takeoff. It was later confirmed that the wing had not been deiced. The pilots have to rely on the ground crew to perform the deicing procedure properly. It is my strong belief that the only way to avoid a similar incident from occurring would be to require a visual check by a pilot after each deicing procedure has taken place regardless of precipitation or the length of time to take the runway. Supplemental info from ACN 230403: There were 40 planes in front of us waiting to be deiced. At 1 point, I was on my jump seat when a hysterical woman came forward shaking, crying, yelling, and cursing, demanding to get off the plane. We had been sitting in line for deicing about 2 hours and everyone was most uptight. As I passed a passenger on my way to the jump seat, she told me she did not think we were deiced on the left side. The captain then asked to be deiced where we were rather than waiting in that long line again. After a lot of disagreeing between the company and the captain, they agreed to deice us again at the freight pad. During this time I answered a call bell to learn that a girl was going into diabetic shock. I ran up to the cockpit and informed the captain, who told the passenger that there was a medical emergency on board and that we are going back to the gate. It was my understanding they only had 2 trucks deicing that night and the trucks had to keep going back to the terminal to refill, explaining the lengthy delay. I asked the first officer why he didn't have to check the wings the first time, when the left side wasn't deiced, and he explained there wasn't any moisture then and there was this time. We finally took off arriving $51 / 2$ hours late. This flight is usually 30 minutes. Our crew had to work on to Pittsburgh arriving at XX15. We were on duty almost 14 hours.

Synopsis: 2 air carrier flight attendants report that a passenger noted that the left wing had not been deiced. The aircraft was on the runway for takeoff. Preflight procedure deicing.

\section{7}

Narrative: Flight XXX (DHN-ATL) EMB-120, 28 passengers. Passenger in seat XX (exit row on EMB-120) had a large duffel bag. I attempted to gate check the bag. The passenger wanted to keep the bag. I spoke to the passenger twice and told him to put the bag under the seat as far as it would go. I told him to push it with his feet. I pulled it all the way forward to the bar beneath the seat in front. The bag was secured. It was protruding approximately 6 inches. As the flight attendant, I did not feel this was an obstruction (the exit row) compromising the safety of the passenger. The man still had ample room for his feet. I made all required announcements. Upon deplaning, passenger in seat XX asked why I allowed the row to be blocked. Not knowing at this time who he was, I explained the bag was securely stowed. Passenger in seat XX said the bag was too large and he thought it was a violation of the federal aviation regulations. Passenger in seat XX then stated he was an FAA inspector, only upon leaving the aircraft. The problem arose by trying to combine safety and service and complying with both. Also, there was a maximum of passenger and bags because of the weather and ' 0 ' fuel weight of the aircraft and we were trying to accommodate all concerned. Furthermore, passenger should be more aware of exactly why flight attendants are on the airplane. The problem did not arise until the end of the flight when the passenger in seat XX stated he thought this was an obstruction. The corrective action, if any was needed, was not mentioned until the end of the flight. Perception and judgment factors were both involved because it is one person's perception of what is too big and if the aisle is still passable. EMB-120 has 1 flight attendant to make the decisions in the cabin. That 1 flight attendant has to be 'perfect' at all times with no one else to assist him/her. Also, it was the last flight of 8 flights in a 22 hour period with 8 hours on the ground. The lack of rest contributed to the alertness of that $1 \mathrm{crew}$ member and his/her judgments. If this was truly a compromise of safety, it should have been brought to my attention before the plane left the gate in Dothan. Callback conversation with reporter revealed the following info: flight attendant states that there is a lot of pressure from the company to 'just do your job, but no substantial training, and no backing,' to promote job performance. Then, 'it seems that all the passenger thinks that you are there for is pretzels and peanuts.' Reporter was reminded that the flight attendant position is required by federal aviation regulations, and the job's primary focus should be safety. Flight attendant stated that this is not the company's representation of the job description, but that others have conveyed this attitude. Reporter agreed that one can assert his/her position in a manner that would still meet with the company's service orientation. Reporter's call to Dothan revealed that the inspector was traveling on business unrelated to this company's operation, and that FAA person was not an ACI for this air carrier.

Synopsis: After a flight segment was completed, an FAA inspector passenger identified self, and questioned the flight attendant regarding stowage of a passenger's bag. The inspector asserted that the bag had not been stowed properly and that this was a violation of federal aviation regulations.

\section{0}

Narrative: I am uncertain of the legality of the times and was the crew legal to continue the next day? Supplemental info from ACN 330381: Duty began XA20 EST at EWR. Itinerary: EWR-ATL-TPA-MDW with duty to end at MDW at XI25 CST, for 9 hours 5 minutes and 5 hours 49 minutes 
flight time. We finished with 10 hours 12 minutes flight time and 18 hours 45 minutes on duty. I'm a sure candidate for more than 30 in 7 and more than 8 in 24, but a careful check of federal aviation regulations and the interpretation of having flown as scheduled and continuing within the intent of our itinerary allowed us to finish at MDW, legally. We arrived ATL when the fast moving weather (windshear) necessitated abandoning approach at $200 \mathrm{ft}$. Airport closed, we diverted to CHA. Refueled on to ATL, then on to TPA. Enroute to MDW, unexpected heavy snow closed airport (below minimums). Diverted to Rockford, IL. RFD fix-based operator did a great job but the staff was overwhelmed since 10-12 aircraft also diverted there. We finally had buses to take our passenger but had to leave 7 behind (all elderly). Passenger had to walk 200 $\mathrm{ft}$ ramp on ice into 20 plus KT wind at 10 degrees Fahrenheit. Security wouldn't allow buses to aircraft, but loaded buses came to aircraft. Flight crew transferred bags in miserable conditions. (There's much more to this story though.) We finally flew RFD to MDW, exhausted! (with 7 passengers.) A 30 minute flight, but took 1 hour 47 minutes which included 1 hour 5 minutes on ground at MDW awaiting a gate. We all watched 8 in 24 closely. Company wanted us to Part 91 Ferry to avoid 8 in 24 , but passenger (7) had to go (age, infirmity, etc). We were assured of legality since we were not scheduled more than 8 in 24, nor were we rescheduled to another destination or as a different flight number. As a small company, we tend to do whatever it takes to keep it going. So it is very possible a sitituation like this can lead to an inadvertent boo- boo! Let others beware. The fatigue factor is a real danger too. But we deliberately discussed this and took extra precautions while operating as the day wore (us) on. Know the regulations! Work closely with crew schedule/dispatch and practice good CRM. (This was the wildestination day in my 44 years of flying, 30 with airlines.) Callback conversation with reporter ACN 330380 revealed the following info: reporter flight attendant was contacted because in her report she requested feedback. Their flight crew finished the day with 18 hours 45 minutes of duty time and 10 hours 12 minutes of flight time. The pilot flight crew as well as the flight attendant crew were all concerned about their legalities under the federal aviation regulations. After arriving at MDW, they were sent to the hotel for a short night and took the flight out the next morning. They had arranged ahead of time with their company that they would fly only the one leg and then be relieved for rest. Reporter flight attendant says the entire flight crew went into their president's office and relayed the difficult trip, and that after such a trip they needed more rest. The legalities are very hazy and not spelled out in the federal aviation regulations. When there are irregular operations due to weather conditions, there are limited guidelines which apply and mostly are contractual items. Reporter says the president was sympathetic and guaranteed that they would handle the rest period better in the future operations. Synopsis: Flight crew contended with numerous weather problems extending their duty day to over 18 hours. Legalities were maintained, however, though the rest time allotted to the flight attendant at the conclusion was questionable.

\section{4}

Narrative: Scheduled for federal aviation administration mandated recurrent training on Sep/XA/97. If recurrent training is counted as a part of or applies to the 24 in 7 rule then I worked 7 consecutive days without a 24 hour break.
Originally, I was scheduled to work 4 days of reserve on Sep/A,B,C,D/97, I then picked up an additional 2 day trip on Sep/E,F/97 for a total of 6 days of work. Moments later recurrent training was assigned to me for a total of 7 days. Although I addressed this issue with our scheduling dept, I was told recurrent training does not count towards a part of the 24 in 7 rule. I'm still uncertain about this federal aviation regulation. Synopsis: Cabin attendant questioned the legality of scheduling recurrent training on the seventh day of duty without having 24 hours off duty. Company said that cabin attendant training is not included in company duty time for computing rest periods.

\section{0}

Narrative: On Nov/XA/97 at XX00, DCA-HSV was delayed causing a delayed arrival in HSV. Upon checking out at XX30 the crew did not realize we were not going to have the entire scheduled reduced rest period. The time change from eastern standard to central could have added confusion. Also the company's current crew track system did not flag our section to advise us of the need for a delayed check-in for the following day. We checked in at XA36, our scheduled check-in time. Still not aware of not getting our full 9 hours of reduced rest, the following day I was advised by my crew that we did not get enough crew rest. Crew scheduling had called the captain. Synopsis: Cabin attendant reported less than scheduled rest due to the flight being delayed in starting from the origination point which caused it to terminate later than scheduled and consequently less time than scheduled between the next duty starting period.

\section{9}

Narrative: At origination we were delayed due to the valve problem in the \#1 engine. It was fixed and logged in the book. Meaning we were signed off that it was fixed. We took off and felt no incident until we got a phone call from the captain stating that he shut down the \#1 engine and that everything was okay, that we were 40 miles from MIA and we did not need to prepare the cabin for an emergency landing. We landed with no incident and the same aircraft was repaired and as for the flight attendant crew I was on we went illegal to fly because too many hours on duty. The flight went out with no further incident. Synopsis: Flight attendant report regarding B727 engine valve problem requiring an engine shutdown and a return for maintenance. This resulted in cabin attendant illegal duty time.

\section{7}

Narrative: I worked a flight from Chicago to Los Angeles. I was \#1 flight attendant. Some background is necessary to explain my reason for medical attention. I had been on a diet for 2 weeks which consists of no caffeine, no sugar and no carbohydrates. Prior to my flight in Chicago, I drank an extra large coffee (with caffeine), as our flight was a late departure, and it was a long duty day due to a schedule change. Approximately $21 / 2$ hours into the flight I felt strange. My initial thought was hypoxia. I asked the other 2 flight attendants if they felt unusual, and they said no. My next suspicion was possible hypoglycemia. I drank orange juice, had some sugar and water. Nothing helped. From my first aid training, I deduced that I might be having the symptoms of an oncoming seizure. \#4 flight attendant made a public address asking for a doctor or medically trained person, however there was no response. I felt progressively worse. The first officer took my pulse, and asked 
if I felt that an emergency landing was necessary. There was absolutely no doubt in my mind, I felt that this was a potentially life threatening situation. We diverted to Las Vegas. Paramedics met the flight. I was put into an ambulance, and taken to the hospital. The emergency room physician determined that I had an acute anxiety attack due to the caffeine that I drank. He said the diet I was on is not safe. I learned later the diet dehydrated the body, and affects the electrolytes, and also causes low blood sugar. The doctor felt that a CAT scan and blood work was not necessary. My vital signs were normal, and I was released. Overnight arrangements were made, and I flew to Los Angeles. I went directly to my physician (internal medicine/cardiologist). He gave me an EKG and performed blood work. He concluded the same as the doctor in Las Vegas, due to the diet, I had an adverse reaction to the caffeine. No further medical treatment was necessary. I was immediately released to full duty, and assumed my normal flying schedule. Synopsis: At cruise, onboard MD80s, cabin attendant became ill and flight crew diverted to alternate to get medical assistance.

\section{4}

Narrative: A cleaning agent was used on ovens that became toxic with fumes and smoke once ovens were turned on. The smell was 'extremely powerful' before ovens were turned on -- which became smoky once ovens were 'on' and 'heating,' creating nausea, fatigue, headache, as well as a feeling of heavy breathing due to the inhalation of 'smell and smoke.' All cleaning agents should be checked before being used on these ovens. Callback conversation with reporter revealed the following information: Reporter states that the flight diverted to RDU instead of continuing to DCA as scheduled. The flight attendants were taken directly to the hospital. There were no long term effects and the reporter was back to work again after a 48 hour recovery. Several different bases were checked to determine what kind of cleaning agents are used. Some of the bases use only soap and water, others use a variety of cleaning agents. They were unable to find out just what was used in these ovens. Reporter believes this aircraft had come from Cancun. The company is aware and hopefully will follow up. Synopsis: Flight attendant report regarding the noxious and toxic fumes, then smoke once ovens were turned on. The smell caused nausea, fatigue, headaches and a feeling of heavy breathing. Flight diverted. Cabin attendants were taken to the hospital.

\section{7}

Narrative: An auxiliary door light came on in the cockpit after takeoff. This has been written up repeatedly in the cabin $\log$. When the captain contacted dispatch, he was requested to 'go-on' and to take this airplane. He elected not to, and although we did not evacuation, he asked us to go over our commands to ourselves and to know that it was possible we would blow tires due to being heavy. We returned without incident. The cockpit crew were illegal and said they did not discover this until we were airborne. My feeling is they had enough to do without also having to establish their legality. I was not happy to hear that dispatch asked the captain to ignore the sanitation and to continue on. We got to Madrid 6 hours late and were totally exhausted. Supplemental info from ACN 441258: The landing seemed to use most of the runway, but was otherwise unremarkable. Supplemental info from ACN 441259: the fire trucks checked us out and aircraft was allowed to taxi in.
Synopsis: multiple flight attendant reports, B767-300, MIAmad, aux door light on, return to MIA, heavy, maintenance.

448619

Narrative: Completing meal service in main cabin ready for movie to start. Informed of fuel leak and we would be turning around going back to LAX. Landed 20-25 minutes later. Kept passenger calm. Remained on taxiway for some time. Then we got a gate. Passenger were wanting off. After some time -- 40-45 minutes -- passenger told to get off and change planes. We stowed catering equipment and went to the new plane DC10 (lower lobe). Cockpit went illegal, went to hotel. We were not released until XA00. Arrived hotel around XB00. Pick-up the next morning at XM30. Continued on to HNL, arrived XR45. Pick-up at hotel in HNL XR30 on Aug/XB/99. Arrived DFW on Aug/XC/99 at XA00. Returned home and that night I was exhausted -- more so than usual. The hours of sleep being different and not getting a good night's rest on the trip may have contributed to my restlessness or jet lag when I returned home. My next trip is not until Aug/XG/99 and I need every bit of that to recover. Synopsis: Flight attendant report, DC10, DFW-HNL, fuel leak, return to LAX, flight canceled. Pilots went illegal, cabin crew did not, but had minimum rest.

\section{6}

Narrative: Flight attendants are sent out on red-eye flights on the same day they arrive from a transpacific/transatlantic flight. Then some are forced to work an additional segment immediately after the red-eye. Our concern is a safety and health issue. We are fatigued, exhausted, and believe it or not -- jet lagged! We are pushing the line on physical functionality should we be required to perform and react to an emergency. It is ridiculous that this is even legal, as this is physically and mentally horrid. One of the reasons why this occurs is airline $\mathrm{X}$ is constantly short-staffed flight attendants. Already this year, 300 newly hired flight attendants quit airline to pursue other airlines and opportunities (airlines y and z). This is because of airline X refusal to work with employees to settle labor disputes, refusal to settle a flight attendant contract, low pay and poor work rules at airline X. Solution: flight attendants need a contract with decent pay and retirement, we need health regulations. Unless regulations are made, airlineX management will continue to unravel at the safety of the airline like a ball of string. Because of airline $\mathrm{X}$ poor management decisions, the flying public was taken advantage of enough, and the passenger's bill of rights arose. Now the flight crews have had enough, and we want and are in desperate need of a bill of rights for our safety and health. If you are on a flight and an emergency occurred, what kind of flight crew do you want to be with? What would increase your chance of survival? Please help make our airline safer. Please help us to maintain the safety and health of our crews. We appreciate any support and guidance in helping to direct airline X to be a safe United States carrier. Synopsis: Collective flight attendants from airline X, a report on lack of federal regulations for cabin attendant fatigue duty time and rest time. Safety issue.

453948

Narrative: In conjunction with the enclosed report to airline, the 2 main issues that concern me and that I feel should be investigated are the $151 / 2$ hour duty day that the cockpit and 
flight attendants worked, as well as the unsanitary conditions of an aircraft without any running water for approximately 7 $1 / 2$ hours that passenger were onboard. I was flight attendant \#5 from JFK to PAP on Aug/XA/99. We arrived late from JFK. When we arrived in PAP, we were informed that our aircraft was to be used for the PAP-MIA trip which had been delayed from the day prior. We had a decision on our aircraft of XA00 local time, awaiting parts and mechanics from MIA. Once they arrived we went to the terminal to wait. During this time, we were told that if we left, we would not be catered -- no water would be added, and no ice would be brought on -- there would be no water in the lavatories as well. At approximately XA00, we all went back to the aircraft and began boarding about 15 minutes later. Passengers were angry and frustrated when they came on, especially after they found out that there would be no catering or water onboard. They said they were not informed of this at all in the terminal. After all the passengers were onboard, we were told that we would be receiving sandwiches and sodas in a short while. A short time turned into a long time. Passenger starting hitting call lights, wanting to know how much longer. I was in the aft cabin with the 4L door still open with air stairs attached. At approximately XA00, about 2 hours after boarding, I saw a whole crowd of people standing and yelling inciting a riot. At that point, call lights were going off one after the other. At that point, I was feeling uneasy in the back of the plane, but the $4 \mathrm{~L}$ door was still open, so I felt like I could still get out if I needed to. The shouting up front continued to worsen. I went into the cabin for a minute to listen to a public address the captain was making, telling everyone to sit down or we weren't leaving until they did so. No one listened -- it only incited them further. When I returned to the rear, the $4 \mathrm{~L}$ door was closed and stairs removed. The shouting was persistent with more people standing. At that point, I was feeling trapped and unsafe in the aft cabin. I decided to move up to the forward part of the aircraft, where I figured the rest of the crew was. I fought my way through the crowd, yelling, pushing and climbing over bags. I felt a little bit better once I was with the rest of the crew in the forward galley, closer to an open door. The captain was not doing much at this point to control the sit, except make loud remarks so that first class could hear, like 'if they can't take a joke, screw 'em.' the crowd did not relent. I expressed my feelings to the crew that I did not feel safe onboard the aircraft. Many others expressed the same. At this point the captain was on the megaphone -- telling everyone to calm down, that the food would be there any minute. That seemed to get them even angrier. This went on for about 20 minutes, when the purser said he no longer felt safe and was leaving the aircraft. At that point, I said, I no longer felt safe onboard and I told the crew and the captain that I was leaving. He was still talking on the megaphone and had no control over the sit. Flight attendant \#2 and myself waited on the ramp by the gate area -- 3 other flight attendants came out also and said they did not feel safe on the aircraft (this all happened about XA30 local time). The flight attendants then came out, said it was still out of control onboard. The ground staff was trying to convince us to go back onboard so the flight could leave. A few minutes later the captain made a plea to flight attendant \#2 over the megaphone to return to the aircraft and speak with him -- we did not go back -- feeling it was still unsafe. Shortly after that another flight attendant came out and said it was a little better onboard. All but flight attendant \#2 and myself returned to the aircraft.
Everyone kept trying to convince us that it was safe. The door to the aircraft soon closed and stairs pulled away -- ready to depart. We were inside the terminal and asked for assistance in getting a hotel and transportation. About 10 minutes later, a manager came and told flight attendant \#2 that she was confident that it was safe for us to return. Flight attendant \#2 had flown with her many times and trusted her judgment. At that point I decided it was not safe for me to stay in PAP by myself and I opted to return to the aircraft. After I returned to the aircraft, flight attendant \#5 told me that when the captain returned onboard after he tried to convince me and flight attendant \#2 to return, he said in front of the crew and the first

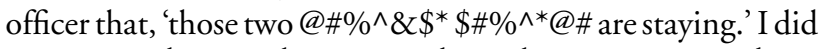
not say anything to the captain about this statement or about anything else. I continued to perform my duties as a flight attendant throughout the remainder of the trip. The lavatories and the rear galley were disgusting and unsanitary -- there was no running water in the lavatories for the $31 / 2$ hour flight to JFK, plus the $21 / 2$ hours on the ground with passenger onboard. I feel that my safety and well being was compromised by air carrier $\mathrm{X}$ airlines, represented by captain and that I was viewed in a discriminatory fashion by air carrier $\mathrm{X}$ airlines in the comment expressed by captain. No further incident took place onboard the flight to JFK. Callback conversation with reporter revealed the following info: the reporter said that the company has reviewed the case and has chosen not to do anything about it. The captain has denied ever calling them names. The reporter feels that this must violate public health laws and believes that it violated federal aviation regulations. He feels that the whole sit was shoved underneath a rug and forgotten about. He said that the Port au Prince and Santo Domingo flights were notorious for the passenger getting out of control. He may try calling the public health board to get some action on the sanitary and safety issues involved. At the present time, he feels helpless to change the airline's policy of taking and accepting an airplane with no water on a long flight. The company told him that because there were a couple of bottles of water onboard, they considered it to have running water. Synopsis: Flight attendant report, A300, Port au P-JFK. Airline and the captain accepted an airplane with no water at all. Passenger rioted and were out of control after 3 hour delay.

\section{0}

Narrative: A passenger rang call light. I found passenger having a seizure. She stopped breathing and was unconscious. The cockpit decided to make an emergency landing in LNK. The passenger regained consciousness within $1-11 / 2$ minutes. Paramedics met the flight. The passenger was removed. While refueling, there was a fuel spill and fumes entered the cabin. The cabin temp was very warm and air conditioning increased the fumes in the cabin. The air conditioning was turned off. Passengers were complaining of heat, eyes burning and throats burning. I wear contact lenses -- my eyes and throat were burning also. My contacts had to be discarded per my eye doctor's instructions. I think the captain should have allowed passenger and crew off the aircraft and away from the fumes. This would have prevented many passengers from vomiting and a lot less stress. We took off and landed safely in LAS. Crew only had 8 hours rest and had to work next day. I think rest should have been longer after such a stressful sit. Synopsis: Cabin attendant report, MD80, ORD-LAS. Passenger had seizure. Divert to LNK. Passenger removed. Fuel 
spill in LNK. Passenger and cabin crew got sick from fumes. Minimum rest in LAS.

\section{4}

Narrative: Attached are 4 pages of notes from my flight log regarding the unhealthy air quality on some of our DC10's. SFO-HNL, dating from Nov/XA/99, to the present. The stinky, stuffy, stale, stagnant, dirty, and chemical smelling air, lacking in breathable air, becomes a problem for passenger and working flight attendants when all the pack flow control switches are not set on normal (high), or when two are turned on low. Some of the symptoms of breathing this poorly ventilated air include: shortness of breath, difficulty breathing, headaches, stuffy or drippy nose, congested lungs and sinuses, sinus pain, sneezing, sore throat, coughing, head cold, burning and tired eyes, pressure behind eyes, tearing eyes, lightheadedness, dizzy, weak extremities, muscle aches, tired, sleepy, lethargy, fatigue, stress, and reduced mental capacity. The lack of adequate ventilation in the aircraft reduces air quality by permitting pollutants to accumulate. Some of these pollutants may include carbon dioxide, produced by dry ice and human breathing, atmospheric ozone, fibers and dust, formaldehyde in carpets and seat material, nitrogen oxides, volatile organic compounds from fuel, cleaning fluids, a mix of toilet chemicals, dirty air filters, pesticides, possible cigarette smoke residue, and bacteria, fungi and viruses from passenger and food. It is a known fact that increasing the ventilation flow rate, as within other microenvironments, improves public health, reduces symptoms, and decreases the risk of contracting illnesses and airborne bacteria and viruses. Contrary to the company's manual position that passenger comfort is increased by reducing air flow noise, cabin conditions on these old DC10's are such that passenger comfort is adversely compromised by reduced air flow, as is the health of working flight attendants, resulting in possible toxic chemical poisoning. Flight attendants have a right to a workplace with full utilization of air. An aircraft is an environmental control sys. It is not only the aft cabin that has poor air quality, it's the entire passenger cabin, lavatories, service center and galley. Zone A, $\mathrm{B}$ and $\mathrm{C}$ are not confined, isolated self-sustaining entities, but a single, self-contained aircraft. Knowing the poor air quality ventilation consequences of not operating with all 3 pack flow control switches on normal, it has been standard operating procedure for most pilots to leave them all on during flight, or at least to turn them all on normal when advised by flight attendants of lack of ventilation. Is company policy on pack settings different than flight manual ? After 34 years of flying, and probably the last 20 years on DC10's, a concern for my own health and that of my flying partners and our passenger is my priority in reporting this ongoing problem. In these last months of DC10 flying, there is no time to waste in resolving this issue. Synopsis: Cabin attendant report, DC10, SFO-HNL. Sites airline's DC10 manual for air flow packs set on low, or \#3 turned off, for passenger comfort as being the opposite: health threat for passenger and cabin attendants.

\section{9}

Narrative: We were reassigned at the last minute off our deadheading back to SNA to work a full B767-300 DFW-MIA because the cabin crew had gone illegal. It was very chaotic with the illegal crew getting off and the 3 of us trying to get on. The passenger service manager or lead agent had told us that we were a minimum crew of 5 and that 2 deadheaders on the flight had been informed that they would be our \#3 and \#5. She read out our names and position as we got on the plane. We didn't have a crew list. I had been assigned purser. I am not a qualified purser. As the illegal flight attendants got off the aircraft, we also asked them if the 2 deadheaders had been contacted that they were to work and they said 'yes.' as soon as we got on I went up to the cockpit to introduce myself to the captain that we were a minimum of 5 -- stowed luggage, checked emergency equipment, the door closed, and we prepared for departure video safety checks. As we took off, I noticed that the \#5 had not gotten to their jump seat. I was thinking that the \#5 had taken the wrong jump seat for takeoff and must correct them for landing. I went up to the cockpit to get the crew list. The captain did not have a working crew list, but did have a list of all the deadheaders that were originally scheduled to deadhead. I went to the \#3, who was originally scheduled to deadhead, but was now working to point out the other 2 deadheaders to me. I got them in the galley and asked who was supposed to be working \#5 position. They both said that they had not been contacted to work. I said, you are both working now and designated one to sit the \#5 jump seat $1 \mathrm{RC}$ for landing. I informed the captain that the other 2 deadheaders were working and I had designated \#5 for jump seat for landing. To prevent a reoccurrence -- all flight attendants must work their assigned position and sit in their proper jump seats. I won't be pressured by the ground crew to get a flight out, especially in a chaotic sit like we had. Even if I have to cause a further delay, I will make sure the captain has a briefing with me (he's supposed to anyway) and I have a briefing with flight attendants assigned to work. Supplemental info from ACN 476405: the only problem -- door 1R was not manned during takeoff. I was not informed of this before takeoff. Synopsis: Multiple pilot and cabin attendant report, B767300, DFW-MIA. Original cabin crew illegal. 3 cabin attendants grabbed off another flight to work (FAA minimum 5), including 2 deadheaders. In the confusing crew change, door 1 unmanned for takeoff.

\section{3}

Narrative: Flight X was delayed due to maintenance. There was no air on aircraft. Maintenance signed off. We pushed back. We had no air. It was about 90 degrees in the back of aircraft. It took about 20 minutes or more to take off. We took off and still had no air. Mothers were taking the clothes off their kids to get cool. Everyone was upset on how hot it was. We were then informed that we were returning to DFW. We were told to watch for smoke in the cabin and fuel smells. The fire trucks met us on landing. They got out of their trucks to give our aircraft a visual. Still no air. We taxied into the gate. We deplaned. We were met by an inflight supervisor and given the option to be pulled from the flight if it continued. We (all 3) were pulled. We did not evacuate the aircraft, but we did in our minds. We were set to go! Not one of us (the flight attendants) had a dry piece of uniform on. We were removed by choice for safety reasons. We were spent! We now have marks on our record. Pushback from gate to landing was 53 minutes. Add 30 minutes for boarding full aircraft with no air conditioning. Callback conversation with reporter revealed the following info: The reporter stated that she didn't know if the cockpit had any air when they accepted the logbook signoff, or if they were aware that they were going to take a plane with no air. Once the problem became apparent in the 
air, some of the elderly women started to panic and came close to passing out. The captain never told the cabin crew why they were to look out for smoke, nor did he communicate with them about the nature of the problem. After landing, the plane was taken out of service and another plane was brought in. The company docked the flight attendants a day's pay for walking off the trip and it went on their records as a negative. Synopsis: Cabin attendant report, B727, DFW-MCO. Maintenance delay, no air on aircraft, maintenance signed off. Takeoff still no air return to DFW. Emergency fire equipment met flight, passenger upset, cabin attendants removed from trip emotionally drained.

\section{0}

Narrative: Flight \#XX SFO-HNL DC10, aircraft \#1, \#2, \#3 all have had major mechanical problems -- many with a loss of the engine, hydraulics, oil leaks, loss of \#1 engine. Jul/ $\mathrm{XX} / 00$ we lost the \#2 engine on aircraft \#2. Jul/YY/00 (my flight that aborted this takeoff.) We had extreme delays with crews duty days, 16 hours long. 2 flights returned Aug/XX/00 after 1 hour in the air. Also on flight \#XY, all 10 flight attendants walked off the plane. On Jul/XX/00 they/we refused to fly after the mechanical delay and we aborted the takeoff. Supplemental info from ACN 480917: there have been major delays and cancellations due to the condition and age of the DC10's flying this route. The concern by flight attendants flying this route has been so great that they have been refusing to work on these airplanes because they feel they are unsafe. Synopsis: Multiple cabin attendant report, DC10, SFO-HNL. Aborted takeoff, loss of engine\#2. Report of multiple mechanical delays for DC10. 10 cabin attendants refused to fly it, due to fear for own safety and walked off flight.

\section{3}

Narrative: I was not involved in the incident. I was flight attendant \#5 working first class galley. However, I do have some input. Every time XHJ are sold on a B767-300, there is always a problem. There was no need, on that day, to give out $\mathrm{XHJ}$, as the coach cabin had lots of empty seats. These seats should never be sold. Flight attendants also have rights. Passengers expect us to shut off the light, be quiet, etc. I cannot sit in a dark galley on an insert (bin). It is inhumane. I always fly either \#4 or \#5, so I also encounter problems when those seats are occupied. This, in my mind, is a major safety issue. Callback conversation with reporter revealed the following info: The reporter stated that she was working in the first class galley and heard loud voices, when a call came from another flight attendant to the purser to immediately come to business class for a passenger assault of a flight attendant. According to the purser, the incident started on the ground. A first class passenger, who was a big, burly man, took his wife some champagne back to coach, where she was sitting. She happened to have been booked in the crew rest seats, which are across from the business class galley. The company is not supposed to book these seats if the flight is over 8 hours, and should not book them when the plane is not full, because the business class flight attendants use them as a vital extension of their small galley. At this point, it is unclear if the assaulted flight attendant chastised him for bringing his wife some champagne, but the wife told her husband that the flight attendants were nasty to her. Later in the flight, words were said and the man had pinned the flight attendant's arm against the fuselage wall, injuring her.
She was heard screaming and crying. The pilots were told of the incident, but did not leave the cockpit. The injured flight attendant didn't go to the layover hotel, because her arm was injured and she was traumatized, so she wanted to deadhead home immediately. She is now in the process of suing the man. No authorities met the flight to interview or arrest the man. Synopsis: Cabin attendant report, B767-300, JFK-CDG. First class passenger (man) assaulted cabin attendant working in business class, injuring her arm over dispute about wife in coach.

\section{1}

Narrative: Passenger X was our passenger on our flight on Sep/XA/00, JFK-GIG. He drank a lot, but was an amiable passenger. Mr. X returned with us on sep/XB/00, GIG to JFK. Again he drank a lot, but remained calm, quiet and friendly. After meal and duty free service were completed, flight attendant \#4 came to first class to inform me Mr. X was now sitting on the floor at our flight attendant crew rest area. Previously he had nearly fallen on top of flight attendant \#4 in the galley. I approached Mr. X and asked if he was all right. He said he was anxious and depressed. I asked him if he wanted to talk about it. My crew pitched in. They watched the cabin. They started paperwork. I spent the next $2+$ hours talking with $\mathrm{Mr} \mathrm{X}$. He expressed great sadness in his life and feelings of depression. He indicated he was an alcoholic (off the wagon) who began drinking again on our trip on Sep/XA/00. He had been sober 125 days. He indicated he wanted to hurt himself on several occasions during our conversation. He said he was on prozac. I mentioned combining prozac with alcohol was not a good idea. Mr. X said he had been abusive on a pervious X airline domestic flight. He was drunk. He hit a wall and seat backs. That flight the captain came back and talked with him. He said the FBI removed him from the plane. Tonight, Mr. X told me he had a knife in his briefcase, and he wanted to use it on himself. I told him, 'we will have none of that. I do not allow my flight attendants, crew, or passenger to be threatened.' I asked to see the knife. He ignored my request. As time passed, Mr. X calmed down. He returned to his seat and put on his headphones. A few minutes later, flight attendant \#8 informed me he had a knife out. I checked. The knife was gone. A minute later. Our flight attendant \#4 said, 'he's holding a swiss army knife in his left hand, tossing it back and forth between both hands. This time, I went to him. I saw him trying to hide the knife. I reached out for it and said, 'give me that. You know better than that. Shame on you.' he smiled, and gave me the knife. I took it to the cockpit. The captain had been advised of entire incident from the beginning. Flight attendant \#9 advised me that $\mathrm{Mr}$. $\mathrm{X}$ has been on previous flights on our airline, and behaved the same way. He got drunk. One of the flight attendants spent a lot of the time talking to him. He then calmed down. He had no knife previously. My concern is, now Mr. X is carrying and bandying around a swiss army knife. He opens and closes it. He pretends to hide it. He admits he had been violent on flights before. My recommendation is, at minimum, refuse to serve Mr. X any alcohol, and secondly, check his carry-on bags for weapons. Once we landed, Mr. X rushed off flight. I informed the agent of the incident in case Mr. X claimed his knife. I do not know what he chose to do once he left our flight. Callback conversation with reporter revealed the following info: The reporter stated that the man was in business class. He sat on the floor in the crew rest area, which consisted of some curtained-off seats in business class. The crew couldn't 
use the crew rest seats for their breaks, because she was sitting on a seat, and the man was sitting on the floor, talking for 2 $1 / 2$ hours. The man had been refused more alcohol several hours earlier, before falling on the galley flight attendant. She believes that he was just playing a game with the swiss army knife, and probably wasn't trying to injure himself. She never asked the captain to call for police or the FBI to meet the flight. Synopsis: Cabin attendant report, B767-200, GIG-JFK. Man flew round trip with same crew, intoxicated, depressed, sat in crew rest area, pocket knife confiscated. History of violence on other flights.

\section{6}

Narrative: Passenger appeared to be having a heart attack. Another passenger noticed him and called for help. A public address paged for a physician, and one responded and assisted us. 2 flight attendants attached the AED to the passenger, I obtained solid state oxygen and turned it on, the physician attached the mask to passenger's face. Another flight attendant obtained a medical kit and physician used nitroglycerine on passenger, who then improved, but physician insisted we land because passenger would not make it all the way to JFK. We landed shortly thereafter (heavy) in BSB, paramedics came on and removed passenger, then we canceled because 8 tires needed to be replaced, 5 of which were flat. Passenger had bypass surgery and was on his way to New York to consult a cardiologist. Passenger forgot to bring his heart medicine. Passenger told no one, and was traveling alone. Problem: Crew waited until every passenger had been given a hotel room, then we were assisted last. We (crew) also had 3 unaccompanied minors with us. The following day we were told by several passenger that passenger who had heart attack entered hotel lobby as last passenger were being checked in, and he and 2 or 3 other passenger from flight stayed up until XA00 am smoking and drinking! Passenger attempted to board plane next day as if nothing happened. He was denied boarding, however, by agents and captain. Synopsis: B767 crew had a passenger heart attack in cruise flight in SBBS class A.

\section{5}

Narrative: Purser came to business class and asked us to come to the galley (position 78 and 4) and explained the cockpit had various inoperative instruments and we would continue to JFK to have the problem evaluated. A very important safety issue that did arise because of this unscheduled landing, delay, etc, was flight attendant crew rest seats. Because of less than an 8 hour flight time, ORD to GLA, all seats plus crew seats were sold. A late night departure, XA00 flight time to JFK, delay to fix the aircraft, flight time JFK to GLA, made for an extremely long night and over 8 hours of flight time. On landing, all crew had been up for at least 24 hours and were exhausted. In business class we sat on plastic inserts to rest, or tried to. Lack of proper rest space, in such a sit, is quite unsafe. One cannot be $100 \%$ in an emergency situation. This is a continuous problem with air carrier X concerning proper crew rest. Synopsis: A B767-200 cabin attendant reports that with long duty time and mechanical flight delays cabin attendants do not have crew rest seats.

\section{4}

Narrative: This flight was diverted from MEX to ACA. Approximately, one and a half hours after arrival a passenger required medical attention due to dizziness. Flight attendant \#2 and \#7 paged for physician and obtained oxygen. 3 doctors responded and requested a flashlight to check her pupils. I was obtaining my personal flashlight when another passenger ripped the flashlight from the wall at door. An ambulance came and passenger was removed. An hour after that, we were finally able to deplane our passenger. Ground services assisted our passenger. During the deplaning process which took some time due to the necessity of using busses and passenger need to clear customs, flight attendant \#2 noticed that another flashlight had also been ripped from the wall. Unlike the other flashlight which was returned immediately the \#2 had to page to ask for its return. It was surrendered at that time. Before the crew deplaned, flight attendant \#2 also noticed that the pin from the halon located behind the last row of seats in main cabin on aircraft right was missing. This was never found or returned. The following day airport security discovered oxygen cartridges (passenger lifevest) with passenger carry on baggage. Lifevest were requested from passenger (by crew) involved and all three were returned. The law enforcement officers in MEX met the flight and removed the passenger who had taken the equipment. This was a ten hour ordeal for our passenger. Four of these hours were spent flying, the remaining hours were chaotic for everyone. The aircraft was hot, our supplies were low, little ice and no food other than snack bars, and our passenger were close to rioting. Additional cabin crew would have helped with crowd control and a faster deplaning process would have helped everyone. Cabin crew was on duty for 17.30 hours. Synopsis: A flight attendant report on loss of control of the passenger on board a diverted airliner sitting on the ramp at MMAA, FO.

\section{0}

Narrative: I was calling in fatigued the previous day and was still made to fly the schedule I was given. I had to go off on medical. They took me off from flying for 24 hours and told me to rest. I was on long days and short overnights. I was not getting enough sleep during the nights. I called my manager and told her I felt unsafe to fly and did not feel I could do my job. The company did nothing to help me in this matter. I was tired and sick and was still penalized for not flying. Over 12 hours is too hard to work and be safe on short overnights. For 3 days I was on less than 9 hours 30 minute overnights and over 12 hours 45 minutes on duty time. I had to file a complaint. I was on reserve duty and all was legal to fly. However, the days I was asked to work was making me tired and sick. I was not safe and even felt lethargic. I went to the doctor and she even said it was not safe to fly so much and so little 'actual time sleeping,' less than 7 hours 30 minutes on each overnight, followed by over 13 hour duty days. We do not get 'behind the door time' (it is 'block in' time) which can be more than a full hour -- a big difference. Synopsis: Flight attendant report regarding the work scheduling that was alleged to have created an unsatisfactory work environment, with long duty days and short scheduled rest periods out of DFW, TX.

\section{2}

Narrative: from our departure in Sao Paulo we experienced a light to moderate rough air (chop). It felt like the plane was traveling so fast it was shaking apart. I called the cockpit once to let them know that we were having a tough time walking 
due to chop and I was concerned that passenger were ignoring the seatbelt sign because it had been on so long. I was told we were trying to save fuel by traveling at this rate and that we were boxed into this alt for now by traffic. The flight seemed to smooth out about $1 / 2$ hour later, but I remember sitting down for my break and being unable to rest due to a constant light, jarring chop. We started breakfast service at XA15, 15 minutes earlier than usual because with the tailwind or speed we were arriving more than 30 minutes before schedule. I was assigned to work R-hand side coach cabin. After I picked up service items and trays in coach, I did a double-careful seatbelt check. I had noticed at least 2 kids sleeping on seats without belts on while their parents were in the lavatory or wandering around. I did strap those little ones in as well as I could and moved to business class. I saw at least 4 trays out. Since we were about 20 minutes from touchdown (landing), I cleared 2 trays and made my way to the galley, bracing my legs in the aisle between the seats. About the time I reached the $2 \mathrm{R}$ door by the entertainment module, there was a hard jolt. I tried to hand a tray to another flight attendant so I could grab something and stabilize myself. I released one tray, then felt airborne briefly, before feeling like a rag doll smashed into the floor. My legs flew out from under me and I landed hard on my right elbow then rolled to my left hip. There was no free hand hold I could grab. I heard lots of crashing china and glassware, the business and first class galley compartments emptied themselves of their contents, much of it landing on top of other flight attendants in the business galley that I could see. It's a miracle no one was cut. I crawled to the $2 \mathrm{~L}$ jumpseat and strapped in. My right elbow was scraped, bruised and swollen. I got some ice from another flight attendant. I made my way back to the $4 \mathrm{R}$ jumpseat for landing and noticed almost complete seatbelt compliance! We were met by the agent and EMS crew and police. Several flight attendants were bruised, sore, limping. I went with the EMS crew and one other attendant to the port auth medical. I do not hold our cockpit crew responsible for this incident. I was very relieved that the seatbelt sign was on and that I knew I had made extra careful seatbelt checks. Injuries could have been prevented if trays had been picked up as soon as passenger finished eating and especially if the galley doors (compartment doors) had been locked. The key is, especially during turbulence, to stow and lock all compartments. I'm sure that saved the aft galley staff from more serious injury. Turbulence happens. In order to diminish the likelihood of injury, remove all flying objects (trays, glassware) as soon as possible, batten down the hatches and make sure you aren't a flying object by staying strapped in when chop is present! Synopsis: In a night operation arrival in an area of thunderstorm activity, there were numerous flight attendant injuries reported in a B777 during descent into JFK, NY.

\section{2}

Narrative: Reported to work on Jul/Wed/03 at XA10. Boarded airplane at approximately XA35 and departed ZZZ. Captain discovered problem with a battery charger and company advised a return to ZZZ1 to repair. Landed at ZZZ1 at XC04. Flight attendants stayed on board with passenger during 2 hour 14 minute time on ground. Departed ZZZ1 at XE18, arriving in ZZZ2 at XG22. Cabin cleared with lights on bright during ground time. Flight attendants called crew tracking to question our legalities for continuing home to ZZZ. Flight attendants all reported feeling very tired at this point. Body time was
Xk00. Tracking stated that as long as we weren't 'scheduled or rescheduled' to be on duty over 14 hours, that we were legal. Reboarded aircraft at approximately XH01 and flew to ZZZ arriving at ZZZ at XP18. Including our 30 minute debriefing, this duty day was 15 hours 38 minutes. Considering the following factors, I strongly believe this trip should have become a layover for the flight attendants in ZZZ2: 1) night flight. 2) not 1 minute of time away from passenger for 'rest break' -- ground time in ZZZ1 and ZZZ2 was not our own time for any rest. 3). Company was aware of our extended duty period from the time we left ZZZ1 for ZZZ2, allowing them sufficient time to remedy the sit (i.e., cancel return flight and put passenger on alternate flights or delay flight until following morning, allowing for adequate crew rest). 4) duty day was showing 15 hours 38 minutes before we reboarded aircraft in ZZZ2. Just because it's not 'scheduled' that way doesn't change the fact that it's 'actually' going to be 15 hours 38 minutes or more. If another incident occurred (delay due to fog in ZZZ or diversion for mechanical/emergency) we would've been way over 16 hour limit. Fatigue (especially at night) leads to errors. Synopsis: B757-200. The flight attendants were scheduled for a 15 hour 38 minute duty day, all night, ZZZ2 turn. The flight attendants complained of fatigue, and did not have the opportunity for any rest break.

\section{5}

Narrative: We experienced a 31 minute delay while waiting for 3 connecting passenger. After several hours in flight, we began to notice that 1 lavatory after another stopped functioning, unable to flush, and filling up. One by one, the lavatories were blocked off and inaccessible for passenger use. Captain (after conferring with many sources), made the decision to divert to SLVR. We were on the ground there approximately $1 / 2$ hour. We then continued on to SAEZ, and upon arrival, we had been on duty 14 hours, 59 minutes. Due to the fact that this was an special flight, the hotel had a cake for us, which was the first food several of us had eaten, as there was little or no food left on board, and we no longer have meals provided for us. When I arrived in my room, I looked at the clock and realized it was exactly 7 hours until pickup for our return flight. This was all the time we had available to unwind/sleep/ shower and get ready to fly again. According to my schedule, the ODL was XA51, but this didn't count travel to and from the airport to our downtown hotel. Certainly no time to have a meal after arrival or prior to departure. Our \#2 flight attendant really felt the effects of this sit -- as he was unable to return with us due to a migraine and total lack of sleep. I felt like I had been beaten up. When we arrived at the airport once again, because it was a special flight out of SAEZ, there was a cake for us. For most of us ate the cake at the hotel and this cake was the only sustenance we had to eat since leaving. ( 2 pieces of cake in 24 hours.) We were exhausted due to lack of layover time to sleep. If our sit was at all legal, then the FAA needs to take a serious look at these limits. Proper rest times are essential as well as time to eat a decent meal. I believe our safety is compromised greatly by the present guidelines. Supplemental info from ACN 598806: flight crew very tired, not sure I could evacuate in an emergency with such little rest. Synopsis: Departure delay and a diversion to an enroute airport for a mechanical resulting in a late arrival at destination resulting in minimum rest along with inability to acquire food for the crew is sighted by a cabin crew as a safety hazard. 


\section{6}

Narrative: I finished business class beverage service, noticed flight attendant \#4 kneeling over passenger. I climbed over flight attendant \#4 and passenger. Another flight attendant handed me AED. I put on gloves and felt passenger's forehead, passenger was sweaty and cold. Doctor arrived and decided we should monitor passenger's heartbeat. I turned on AED while \#4 flight attendant removed shirt and sweater. I tried to shave chest, razor didn't work, passenger had too much hair. I applied pads, AED advised 'no shock advised.' Flight attendant \#4 administered oxygen. Passenger passed in and out of consciousness. Flight attendant gave passenger orange juice. Passenger looked gray. Passenger remained on oxygen until we landed in PIT. Passenger was removed from aircraft in an aisle chair. I wish I was better rested, I would have felt more confident during the sit. 6 hours of sleep plus a headache medicine did affect my judgment. Our layover was cut too short due to a delay leaving the previous day. The sit left me emotionally and physically drained. Synopsis: A passenger on board a B767 became ill resulting in medical attention by the cabin attendants and a doctor that was on board.

\section{7}

Narrative: On the second leg of our trip, we were to fly from SJU-PHL. While boarding the flight, a passenger collapsed on the jetbridge. Paramedics were called to the gate. When they arrived, it was determined that she should not fly. Then, when the last passenger was boarding we were informed that she was claustrophobic. Right as they were closing the aircraft door the passenger decided she could not fly and had to have her deplaned. After these sits, we departed only 10 minutes late. During the first beverage service, a teenage passenger traveling with his father had a seizure. Our $\# 2$ flight attendant attended to him. He seemed fine after the seizure but, during our meal service, he had 2 more seizures. We paged for a doctor but there was no response. After the \#3 flight attendant spoke with the father, who spoke mostly Spanish, it was determined that the father had over medicated his son due to a change of dosage by his doctor that day. The father misunderstood the dosage and gave the son $900 \mathrm{mg}$ instead of $200 \mathrm{mg}$ for the day. After the \#1 flight attendant spoke with the physician on call, it was decided that we would land in TXKF. We deplaned the father and son and, after refueling, we continued to PHL. During the TXKF-PHL segment 2 passengers complained of medical situations. One with a very swollen leg that we elevated and iced. The other did not seem to have an actual problem and was determined to just be nervous from all of the sits that had occurred on this flight. He was comforted and he relaxed and was fine. When we arrived in PHL, we had 5 wheelchair passenger, including one non-ambulatory passenger. Only 1 agent met the flight so the flight attendants assisted the agent in getting the passenger into the terminal area. The pilots were trying to get off of the aircraft as we were trying to get the passenger requiring assistance into their wheelchairs. I made the comment that I didn't know what their hurry was because they couldn't leave without us and we couldn't deplane until all of our passengers were off of the aircraft. When the flight attendants arrived at the hotel pick up point (which the paperwork shows 2 locations) we did not see a van. The \#1 flight attendant called the hotel and found out that the pilots were just arriving at the hotel. We were told that the van would be sent back for us and it would be about 10 minutes. I called crew tracking. I informed him of our sit and our illegality. Our original trip had very little room for delays to make the layover time legal. Crew tracking said to call when we arrived at the hotel for our new sign in time for the following day. When we arrived at the hotel, I called tracking and spoke with a woman. I told her that I had already spoken with company about our situation and, after a moment, she gave us our new sign in time. The flight attendants finished checking in and rushed to our rooms to get some sleep after our 16 hour day. After our emotionally and physically draining day, we did not even think to question the sign in time. We could barely stand, let alone think. We did know that we had a 12 hour day facing us the next day. We finally had a break after the meal service the next day and began writing our reports. We realized that we were not given our legal break the night before. When we pulled up a hard copy of our schedule, we found out that indeed we were sent out illegal that morning. Our legal break was supposed to be the minimum 10 hour rest break due to the over $141 / 2$ hour day (ours was 16 hours). We received 8.27 on paper which equates to about 5 hours of sleep if you go to bed immediately. We arrived at the hotel around XA35 and by the time we arrived in our rooms it was XA50. My wake up call was at XF30. The minimum rest break should be automatically given. We should not have to fight for it. With all of the give backs that we have had to endure, we also have to endure inhumane and unfair treatment? A 16 hour day with no food provided, no sleep, or respect, and yet we perform our jobs with smiling faces and caring hearts. We took care of the many sits that occurred on this flight with professionalism and compassion. A minimum legal rest break is a minimum legal rest break. Crews are not always in the position to fight for it due to the fatigue we are now experiencing on many of our trips. We were on duty for 28 hours out of the 36 hours away from home. How can we be aware, vigilant, and doing the best job possible with long duty days and less than minimum rest breaks? Synopsis: A flight attendant described a difficult flight segment which required a diversion due to a medical emergency, and resulted in the cabin attendant crew being shorted on rest.

611289

Narrative: I went back to my crew rest seat for my crew break. I asked passenger to go back to her seat in first class. She asked me to sit somewhere else. I repeatedly told her that this was my 'rest seat' and that she needed to go back to her seat. Finally, she did. Shortly after that, her husband came back and confronted me how rude I was to his wife. He said he was going to write to my air carrier and I said I would be writing it up also. He got very angry and said mean things to me, then he turned around and walked about 5 rows, turned around and said something else to me (he did this 3 times!). On the third time, he got about 5 inches from my face and I felt (along with another flight attendant) that he was going to hit me. I feel that if flight attendants had confidence within themselves when a passenger confronts them, that the flight attendants would be able to stare them down and the passenger would not attack them because they would realize the flight attendant has no fear and would not put up with their actions. Synopsis: An air carrier flight attendant, attempting to utilize the official crew rest seat for her designated break, was obstructed by a passenger who refused to move. After repeated requests, the passenger moved. The passenger's husband then confronted the reporter and was verbally abusive. 


\section{2}

Narrative: I am writing this letter to express my and my co-worker's concern regarding air carrier XXX following current FAA layover minimum guidelines of 8 hours. As it stands now, when flying current sequences built with 8 hour layovers and 10-13 hours on duty, I and my co-workers are not safe flight attendants. Fatigue impairs my ability to function with a clear train of thought, coordination, concentration, and sound judgment. I find myself acting as if I was under the influence of alcohol, essentially I am working drunk! In this day and age when I and my co-workers are required to be ever vigilant, I find we are not. There are times when I fall asleep on my jumpseat during taxi in and out of gates. I forget the easiest of tasks, including arming my doors for takeoff and giving safety briefings to passenger on an exit row. We are supposed to be aware of suspicious behavior and actions from passenger, but we are not. We are too fatigued to study and look and scrutinize passenger. When tired, most of us assume that all this has been done in the airport, thus leaving more holes in the 'swiss cheese' theory on security. I am writing to NASA to tell you that fatigue is a huge problem that needs to be addressed immediately. The traveling public is not safe in our hands. We are not safe in our own hands. Crew fatigue is so widespread, it is only a matter of time before an accident or serious injury occurs because of tired flight attendants. I hope NASA understands how important proper crew rest is, and can/will put pressure on the FAA to increase FAA minimum crew layover guidelines. Synopsis: Cabin attendant advises that routine assignments of max duty days coupled with minimum rest periods results in unacceptable deterioration in performance of safety related duties.

\section{6}

Narrative: Flight returned to the gate due to a second mechanical problem. During that time the flight attendants went illegal. The flight was canceled. We were taken to the terminal. The agent notified us that crew schedule demanded we work the flight back. We explained we could not work after being on duty over 16 hours. They did not like the answer. The crew personally called tracking and was informed they would get their legal rest and deadhead the next day. The agents were not cooperative, they were upset that the flight had to be canceled. It took us over 2 hours from the time we went illegal to the time we were given crew 'DECS' to clear customs so we could go to the hotel. With $90 \%$ of our flights having 10 hour layovers and 14 hour days, it is no wonder we are constantly fatigued and cancellations have to be made. These long duty days with minimal layover have become the rule, not the exception. Something needs to be done. We get harassed when we call in sick, but with work conditions getting worse, these incidents will probably keep happening. Supplemental info from ACN 653387: We called crew tracking and were told we did not have to work the flight. The agents were upset that the flight canceled so they took their time getting our hotel and paperwork together. These incidents would not happen if we were scheduled reasonable hours on duty. Synopsis: Ground personnel at foreign station demand cabin attendants to fly beyond contractual and reasonable duty time limits.

\section{7}

Narrative: I had a schedule ZZZ-ZZZ1 with a 08:20 departure. My van pick-up time from layover hotel was scheduled for
06:20. At 06:20, I called van service as the van hadn't arrived. I called my airline's hotel desk at 06:30 to report same. At 07:55 and 08:17, I called airline crew scheduling. At 08:21, I arrived at $Z Z Z$ airport and was given a new assignment with a duty time of 13 hours and 24 minutes (ZZZ-ZZZ2 departing 10:55, ZZZ2-ZZZ3 departing 17:15, arriving ZZZ3 19:37 local). I asked scheduling to reschedule to a lesser duty time as I anticipated inflight fatigue given that I had reported for transport at 06:20. The airline schedulers said duty time was calculated from 08:17 when I arrived at airport. I chose to go on 'fatigue' status, in which the airline required me to see the company doctor, pilots are not required to see the doctor. The company doctor had no criteria for anticipating further fatigue, or testing for fatigue, except that I had not yet worked a 12 hour duty day, nor did the doctor take into account my restless sleep the night before. The company doctor took me off 'fatigue' status to return to my assignment. I requested that I be allowed to go home. I received a disciplinary status for not taking my assignment and was subject to company investigation. Airlines should not question a fatigue assertion. Recognize that flight attendant fatigue exists as a work related factor. Duty time should include time spent in scheduled transportation to the airport from a layover, and required phone calls. Flight attendants should not be intimidated by discipline in denying they are fatigued. An airline doctor cannot determine fatigue. Synopsis: Cabin attendant refuses extended duty due to anticipated fatigue which would result.

\section{9}

Narrative: I was the purser seated at 11 on flight XX. We arrived in PHL and taxied to our gate at approximately XA00. After the seatbelt sign was turned off, I released my seatbelts, turned on the cabin lighting 'main on' button and took the interphone in hand. I leaned into the $1 \mathrm{~L}$ door window to view the approaching jet way. As I saw the jet bridge aligning with the plane door, I made the public address announcement for flight attendants to disarm doors. As I leaned into the window, I had my left hand near the door handle and inadvertently took hold of it and began to pull on it. I moved the handle upward approximately 3-4 inches and realized I had initiated the door opening while armed. I felt the tug/resistance on the door to pull away from the frame, but I held firm and was able to grasp the assist handle on the door and secure my footing to keep the door from opening further I was then holding the assist handle with my left hand and disarmed the door with my right hand though the door was out from its frame approximately 6-8 inches to where I could see the girt bar. My first concern was to hold the door and keep the slide pack from falling out from below the door to allow the customer service agent time to retract away the jet bridge from the plane. The slide pack was not out yet from its housing. Once the jet way was clear I considered the positioning of my hold on the door, footing and ability to maintain my own safety. I was not sure if the slide pack, not having fallen out or inflated yet could be salvaged and detached/reattached, so I felt I should maintain the hold I had on the door for as long as I could or until I felt it was unsafe for me to do so. As XXX was helping me to try to secure the door, it kept budging away. Just then I heard the slide begin to hiss as the pack had fallen out further unbeknownst to me. Mechanics who were on the tarmac at a distance were surveying the condition of the slide and its position as the first cartridge began to hiss. They immediately 
told me to just let it go. I knew then the slide would have to be inflated. I released the door then disarmed door $1 \mathrm{R}$. The slide fully inflated and mechanics told me to pull the detach cord to drop the inflated slide down to the tarmac. I did so, then removing the girt bar from the floor brackets. We began to deplane once the jet bridge was brought to abut the plane. I was asked to immediately write a statement and was taken by XXX to be drug tested. In total I must have held onto the door for 20 or more minutes. I arrived at the medical facility at about XB10. I left the facility about XB45 and was at my layover hotel by XC00. I judge the actual time the slide began to inflate at about XA20. Reasons for why I inadvertently grabbed hold of the door opening arm as I now think about it over and over in my mind may be attributed to the fact that I leaned into the window supporting myself with my left-hand near the door handle to assess the approach of the jet way as we are trained to do. The closest handle using the same motion used to disarm the A319 door is an upward motion. It was easily confused in the split second. The familiarity also to which the motion of opening the door is linked to looking outside the window in the posture to assess the approaching jet bridge was newly familiar to me from the many times I had both physically practiced and mentally practiced this opening procedure in training that I had just completed. Ironic as the relative timing of my training is to the event of deploying the slide, the mental connection to opening the door was innately natural in that split second. I had also been ill the days before the trip and somewhat fatigued from this and the early hour of the check-in and lengthy duty day. This was my third and final leg of a 12 hour duty day containing nearly 8 hours of flight time. Synopsis: An A319 flight attendant watching the approaching jet bridge forgot which handle he was holding and accidentally opened an armed door meaning to disarm it.

\section{8}

Narrative: We got reassigned to fly to ZZZ rather than deadhead home. We were exhausted due to a very early checkin time and stressful 2 hour taxi ride to airport. When we got notified of the new trip the whole crew decided to call on fatigue because we didn't feel safe and fit to fulfill our duty as safety professionals continuing to ZZZ which was another $31 / 2$ hour flight. Our duty day at this point was already 7 hours. We then got sent to medical and had to deal with supervisors and such. We were concerned about our safety and our level of fatigue at this point. Even though the trip looked legal on paper it sure didn't feel right physically. A report has been filed with our duty supervisor. Due to the circumstances of the morning, we simply were too tired to feel safe in case of any emergency occurrences. Synopsis: Cabin attendants refuse reassignment due to fatigue.

\section{7}

Narrative: I was very tired on the flight from BDL because of lack of sleep. Unfortunately, I failed to arm doors $1 \mathrm{R}$ and $1 \mathrm{~L}$ before pushback. I did not realize as much until we were climbing out of BDL and were already inflight and not thinking. Because I panicked, I immediately got up and armed the doors. The outcome is doors eventually got armed, but not at the correct time. I feel as though because of my lack of sleep I was a bit off track and easily distracted. Synopsis: Cabin attendant fails to arm cabin door until after takeoff. States she was tired.

\section{7}

Narrative: Day started at XA00 in New York for a $21 / 2$ hour drive to airport. Arrived at XK20, was working FFA position, watched for jetbridge to come over. Made the disarm for arrival announcement. Realized I reached for the wrong handle (they're parallel to one another). I couldn't stop the door from opening. I stepped back and the slide deployed. Contributing factors to this incident are: A319/A320 are not my normal aircraft (I haven't flown one in possibly years) and fatigue. Synopsis: Tired from an early get-up and lacking recent experience aboard the a319, cabin attendant actuates emergency exit door instead of disarming the slide as intended.

\section{3}

Narrative: As a reserve flight attendant, I was assigned and I worked 3 all-night duty periods. After arriving home, I slept 7 $1 / 2$ hours. I was called 8 hours after awakening from the crew desk saying that I needed to report to the airport in 6 hours for check-in. I went to bed and tried to sleep, but I was unable to sleep, as I had just worked 3 all-night trips. I found it very difficult to stay awake on my first leg. On the second segment of the trip I found myself falling asleep on the $1 \mathrm{~L}$ jumpseat as I was the purser. I would never have scheduled myself to work this pattern, but being a reserve flight attendant I had no choice. I was very groggy upon arrival, and had to really think about what I was doing as I was bordering on being fatigued. I forgot to disarm door 1R initially. We took a delay on our next and final segment home which allowed me to take a 45 minute nap, which helped me make it back home. Synopsis: Cabin attendant relates repeated reserve assignments that resulted in fatigue induced errors due to lack of rest and interruption of circadian rhythm.

\section{4}

Narrative: I was off flying for 4 years and have been recalled back from voluntary furlough and returned to the London base recently. Departing London on Nov/XA/06 was my first flight on B767 since I am back to London 2 weeks ago. I have a lot of flying experience on B747 and B777 but my flying experience on B767 is limited. My previous flight on B767 is about 4 years ago. Other than today's flight, my other physical contact and experience with B767 was at my retraining where the emphasis was on repeated emergency mode operation at the doors of B767. I have been assigned to sit at door $1 \mathrm{R}$ and work in business class. During boarding, I was busy carrying out duties in my assigned cabin until I heard the announcement of preparing doors for departure over the public address. I was in the aisle at row $9 \mathrm{AB}$. Once I heard the public address announcement, I immediately went to door $1 \mathrm{R}$. The door was already armed when I got there. I verified it being armed by checking the view ports and the yellow flag was extended. Though I verified, I had no physical contact to the door and the arming lever. I was distracted by some personal issues that I didn't rest well during the crew rest break. We were all tired at the end of the flight. I went back to my jumpseat at $1 \mathrm{R}$ when the 'disarm door for arrival' announcement was made. However, when I got to the door, I didn't stop and concentrate on disarming the door. I grab the distinctive but wrong handle, which is found just next to the arming lever and instinctively, at that moment, pulled the silver handle, the same motion I would have done for disarming the door. $1 / 2$ way in pulling the lever, I realized something was wrong 
and heard the loud noise of the slide. I tried to stop it, but it was too late. The doors opened and the slide had deployed. With this experience, I learn and realize the importance of good thinking before touching the door. It's important that I stop, look and think of the consequences before taking action or touching anything on the door, especially an aircraft I don't fly often. Physical contact to the door is not the same as visual checking. It is important and necessary for me to do the arming/disarming by myself. Had I armed the door, I am sure I would have also in reverse, disarmed the correct lever. Synopsis: A flight attendant recently recalled from furlough with little B767 experience deployed an emergency exit slide during an inattentive postflight moment.

\section{0}

Narrative: This trip combined with the one previous made for extremely bad fatigue and I flew without sleep for 48 hours. I was so fatigued I believe it was dangerous and I was too afraid to call enroute sick list for fatigue because of our stringent sick policy. I could barely function which would make for evacuating a plane dangerous for passenger and crew. When is too much fatigue and concern for safety the time to call enroute sick without being threatened by our sick call policy? Synopsis: An A320 flight attendant comments that her series of trip pairings did not allow sufficient rest and the air carrier's flight attendant sick policy discouraged fatigue sick calls.

\section{9}

Narrative: After working the flight inbound to OGG and sitting for 2 hours 28 minutes with change in aircraft and working the all-nighter back, we were exhausted and delirious. Working a turn like that has a tremendous effect on the body. We all could hardly stay awake. I feel if there was an emergency we wouldn't be $100 \%$ effective. We kept checking on each other and moving around to keep each other awake. I personally almost got into an accident on the way home. Synopsis: Cabin attendant reports performance decrement as a result of fatigue on mainland, Hawaii turns.

\section{5}

Narrative: I was supposed to remain on continuous duty overnight. At around XA30 in the morning I received a call from our scheduling departure and was going to be extended to ZZZ. I didn't really think anything of it but I know that if you work a continuous duty overnight you're only legal for 14.5 hours. When we arrived at the airport to continue back to CLT, I got another call from scheduling saying they were going to extend me once again and put a YYY roundtrip on top of the ZZZ roundtrip. I asked the scheduler if this was legal because I was on a continuous duty overnight and she said yes. I asked them to fax the modified schedule to the CLT crew room and I would get it when we returned to CLT. When we arrived in CLT and I picked up my schedule, I was going to be working until XJ00 and I was only legal to work until XF20. I assumed they made a mistake so I called them and informed them of the problem and told them that I was not legal to work the trip. She kept telling me I was on reduced rest and finally transferred me to the scheduling supervisor. She also told me I was on reduced rest, and I told her I was never informed. Synopsis: Cabin crew member is concerned with the possible illegal schedule with regard to the federal aviation regulations.

\section{2}

Narrative: Crew scheduling in their infinite wisdom, sent an first officer to our flight even though he was close to being illegal to fly, and our flight was delayed. By the time we landed, personnel there told me that if we didn't take off in about 20 minutes, the first officer was going to become illegal and we were going to have to stay there. Furthermore, the other flight attendant was on her 6th day working so she was illegal to fly the next day. Just imagine the mess. So they practically made us rush the boarding process and our safety related duties in order to take the flight out on time. These things happen all the time because crew scheduling tries to exploit people to the max. Even when they have other people that can do the flight. As flight attendants we had to rush through our duties, so it's fair to say that the pilots did so too. Just not safe. Synopsis: Cabin attendant reports preflight safety duties were compromised by rushed departure due to first officer duty time limits.

\section{8}

Narrative: I flew a ZZZ all-nighter turn which made me so exhausted that during the last hour and a half of the trip I became marginally delirious. This work assignment combines factors which conspire against the human capacity for endurance: 1) extremely long duty time (14 hours). 2) high flight time (over 10 hours). 3) no crew meal (and no place to buy one in ZZZ). 4) no rest break (and no crew lounge in ZZZ). 5) all-nighter component (extended duty period straddles 2 calendar days, and effectively wipes out an entire night's sleep). I received the assignment on reserve and reported for work at XA40. Everything was fine during the first half of the assignment, up to and including the deplaning of passenger in ZZZ. Because there was no crew lounge, however, my crew spent the 2 hour 'sit' between 'blocking in' and 'pushing back' waiting on the aircraft. Of this 2 hours, about 1 hour and 30 minutes were consumed by deplaning the inbound aircraft, cleaning and servicing the aircraft, changing the galleys, and re-boarding passenger for the return flight. All told, we had about 30 minutes to relax in passenger seats in relative calm. With respect to the 3 hour time change, we did not leave $Z Z Z$ until XJ21. Nevertheless, most of the flight went smoothly for me until about an hour and a half prior to arriving in ZZZ1 (approximately XM40). I began to feel giddy and remarked to one of my flying partners that features of the aircraft cabin seemed fake, more like a 'mock up' than an actual aircraft interior. On one hand I was fully aware that we were at work, on a 'real' airplane and so forth, but my impression was that we could just as easily have been on an amusement park ride at that moment. My flying partner responded by joking with me that I needed to get some rest. We then dropped the subject. As far as I know, I continued to perform my duties as a flight attendant with proficiency throughout the remainder of the duty period. However, given my apparent state of exhaustion I cannot be entirely sure whether my effectiveness was significantly diminished due to fatigue, sleep deprivation and lack of food, and I could have been performing well below my own personal standards. After landing and 'blocking-in' from my reserve assignment I drove home and came closer to falling asleep at the wheel than I have since a particularly grueling series of reserve assignments in 1998. By the time I reached home I had been awake for nearly 24 hours, and could not function for the remainder of the day. I slept on and off and 
attempted to get myself prepared for my next work assignment. Looking back, I am sure that my ability to execute the many flight attendant responsibilities which are the hallmark of my profession, and which now include the additional role of 'cabin security professional,' were certainly challenged beyond reasonable limits by this particularly arduous work assignment. No single factor made this trip especially hazardous, not the 14-hour duty period, the all-nighter component, the 10+ flight hours or the lack of food or rest. Taken separately, any of these factors can be managed with grace. Indeed, I flew all-nighter transcontinental trips during the entire previous month, and experienced no ill effects whatsoever. Furthermore, I flew a regular ZZZ2 turn as purser -- arguably the most demanding work assignment, the week prior and was 'exhausted' by the end, but not 'delirious.' my professional opinion as a 10 -year veteran flight attendant is that the all-nighter ZZZ turn should be eliminated: it's a dangerous cocktail of fatigue-inducing stressors. Synopsis: A B757-200 flight attendant explains the mental alterations that occurred on an all night round trip with a 14 hour duty period and 10 flight hours without food or rest.

\section{9}

Narrative: Pilots announced 'prepare for landing' on descent. The 'fasten seat belt sign' was not on. It took about 5 minutes of confusion in my head before I could figure out whether or not to call the cockpit and ask them to turn the sign on. Nothing was making sense to me. Do I break sterile cockpit? Is this an emergency? Should I just prepare the cabin anyway? What should I do? Why are we still so high? This was very simple but it took forever for me to figure out what to do as I was tired and confused. If it had been an emergency prep type situation, I don't believe I would have been able to react any better. I am a line-holder and I knowingly picked this trip up by choice ensuring to get plenty of sleep and rest before the duty period began. I also consider myself to be a 'night person' and I performed very poorly on the flight home. Our load was not full in either direction but I also observed the rest of the crew to be sluggish and not sharp. I thought it was only me. This is a concern as the safety on board was compromised due to everyone's dull witted and slow demeanor on the return leg home. I fly all-nighters routinely but never with a long continuous duty day with no rest in between legs or at some point during the duty period such as inflight. This trip sequence is dangerous to the company, the passenger it carries and to the safety of its operation for the following reasons: less reaction time to spot fires or other onboard emergencies such as heart attacks, less vigilance and awareness for potential terrorist type behavior or actions, less ability to adequately handle an evacuate. Synopsis: Flight attendant reports being excessively tired on round trip from west coast to Hawaii.

\section{2}

Narrative: This is a request of an interpretation of 14 CFR 91.13(a) with regard to an actual sleep opportunity received for a flight attendant or a pilot in order to stave off potential fatigue and the possibility of careless or reckless operation of aircraft contrary to 14 CFR 91.13(a). This request is prompted by the following scenario that occurred. Although several examples could be provided, for brevity, one will be illustrated. The flight crew reported at XA00 pm local time. A charter flight was conducted from ZZZ-ZZZ1-ZZZ2. After flying on the 'back side of the clock,' the crew arrived at their respective hotel room at XK34 am local time. The flight attendants departed the hotel on a XG00 pm van to the airport. Total time spent at the hotel was 7 hours 26 minutes. Probable sleep received was 5.5 hours, which assumes a 1 hour awake time off -- pre and post sleep. Concluding, an 8 hour sleep opportunity was not actually received, even though the literal language of the duty and rest requirements for the flight attendants were received. Contrary to the flight attendants rest period, the pilot's rest period was adequate, with a duty period beginning later in the afternoon at $10 \mathrm{pm}$ local time. Question posed: Is an air carrier required to comply with written notification from a flight attendant or pilot to the air carrier of his or her desire to have a minimum of a 10 hour non-reducible rest period, thereby allowing an 8 hour sleep opportunity to stave off potential fatigue and the possibility of careless or reckless operation of the aircraft contrary to 14 CFR 91.13(a)? Note: the 10 hour rest period assumes it exceeds the federal aviation regulation rest required for most common scheduling situations, as air carrier operates mostly domestic flights, and one flag rule route under flight and duty time regulations of: $121.467,121.471,121.481$, and 121.505 . In the event greater than 10 hours or rest was required by the federal aviation regulation's, the more restrictive applicable federal aviation regulation would obviously apply. Flight attendant does not have any legal protection, without adverse employment action, for requesting a non-reducible 10 hour rest period to provide an 8 hour sleep opportunity for all rest periods because such protections should be considered in the general rule making process. But it appears the FAA believes otherwise. The FAA has a concept called aeronautical decision making, the theory behind the practice, which is a systematic approach to the mental process used by all involved in aviation to consistently determine the best course of action in response to a given set of circumstances. Please review the following FAA produced powerpoint presentation. http://www. FAA.gov/about/office_org/field_offices/fsdo/orl/local_more/ media/ppt/adm1.ppt. Note the caption on slide 23: 'the effects of stress and fatigue.' presumably, the FAA expects all pilots and flight attendants to act responsibly by planning for and getting sufficient pre-duty sleep. A rested pilot and flight attendant is in the public's best interest. For example, a pilot needs a high level of alertness to respond correctly to an unexpected engine failure on the takeoff roll, and a flight attendant needs a high level of alertness to provide the leadership role as a safety professional in the event of an unexpected evacuate of passenger. Additionally, if a crew member's physiological makeup needs 8 hours of sleep a day for a high level of alertness, but obtains less than 6 , is the crew member legal? Or, does a low level of alertness provide an equivalent level of safety? With a combined total of approximately 1500 flight attendants and pilots operating air carrier part 121 flights, it should be known that at least some individuals function at a far lower level of alertness after sleeping 6 hours than a typical 8 hour sleep period, even if the duty period is of short duration. Currently some flight combinations are scheduled with a 9 hour rest period, thus realistically, affording a 7 hour sleep opportunity if the flight is on time, and less if the flight is late. If an air carrier is not required to comply with a requested non-reducible 10 hour rest period, then what objective criteria ( 6 hours sleep? 5 hours sleep? 4 hours sleep?) And standards does the FAA utilize in issuing a violation of federal aviation regulation 91.13(a) to a certificate holder for a fatigued pilot or flight attendant? Additional info: From the attached letter, written by assistant 
chief counsel, regulations division, dated Apr/Mon/05: 'Please note that the duty period limitations and rest requirements for flight attendants do not necessarily guard against all forms of fatigue that may occur due to actions or inactions by the flight attendant, the certificate holder, or others. A combination of a change in schedule by a certificate holder and a flight attendant's schedule during non-duty time may combine to create a fatigued flight attendant. Though such fatigue causing circumstances may comply with the literal language of the duty and rest requirements for flight attendants, such fatigue must be considered in determining whether a certificate holder's operation is careless and reckless contrary to 14 CFR 91.13(a).' Synopsis: Air carrier flight attendant requests clarification of crew rest requirements.

\section{0}

Narrative: Flight \#1, 10 hours 17 minutes flight time, zero minute of crew rest between deplaning and boarding. Flight \#2, 9 hours 49 minutes flight time, 28 minutes of crew rest between deplaning and boarding. Flight \#3, 10 hours 2 minutes flight time, zero minute of crew rest between deplaning and boarding. Something must be done to change or eliminate the Hawaiian island turns, especially the all night turns. My concerns are not regarding violations or legalities, but rather the ill effects of fatigue, how it relates to safety, and the possibility of life threatening consequences in the event of an emergency or crisis. Although the flight schedules are within the parameters outlined in the union agreement, I emphatically consider them unsafe. These assignments should either require a layover or, at the very least, 90 minutes of scheduled rest between or during the flights. Air carrier continues to proclaim that 'safety is our \#1 priority' but these types of flight schedules reflect otherwise. The passenger trust their lives with the crews, and the crews depend on each other, but the fact is that fatigue is affecting alertness, response, situational awareness, and good health. Considering that the security threat level has also been elevated in the past few days, flight attendants must be even more alert, aware, and vigilant, difficult when fatigued. On 1 schedule, I was on evening stand-by when assigned the all night flight schedule. I worked as the purser on the flight with intentions to create a positive work environment under less than ideal conditions. I was fortunate to be staffed with an amazing crew dedicated to teamwork, professionalism, and customer satisfaction, however we were all exhausted beyond fatigue, especially apparent during our return flight. We were less alert, slower to respond, and I was concerned about our safety, not only on the aircraft but, off duty, traveling home. It is disturbing to think that the company will not even consider a change until an actual incident occurs. I pray that it will not be at the expense of a life. It is common knowledge that the senior line holders desire these island turns because of the ratio between the number of flight schedule and days off, but the fact is that they seldom fly the entire line for the month. On any given day, 'open flying' reflects a number of their island turns. The remaining island turns are therefore assigned to the reserves, those who fly all month long with stand-by assignments, international assignments, and multiple domestic assignments containing short layover periods. In comparison, the reserve does not have the same amount of rest as these senior line holders. They are not prepared physically or mentally, especially when on stand-by, for an all night assignment consisting of a 12-14 hour duty period, 10 hours of flight time, layover time consisting of only deplaning and boarding, and no crew rest. The company has found an international loophole in the union agreement that allows for long duty periods with no crew rest while keeping within the legal parameters for these flight schedules. These flight schedules may not technically qualify as a 'non-stop international segment,' but as with my last 3 ZZZ1 turns, the flight times are comparable to a 'nonstop international segment,' when one considers that there was no layover or rest time between flights. Supplemental info from ACN 714721: This is a scheduled flight schedule that is unsafe in that the flight attendants are on duty for too many hours and into the night. Checking in at XA00 to get back at XM00 is too tiring for the crew. I felt that the crew, including myself, was too tired when arriving to ensure all doors were disarmed. I believe this flight schedule is unsafe and should be evaluated as to whether it should continue as scheduled. Synopsis: Flight attendants describe scheduling practices that are legal but may be causing undue fatigue among the crews.

\section{8}

Narrative: I became ill while delivering the all-nighter snack service. I was dizzy, I had a headache and an upset stomach and was very disoriented. I had to sit down and rest numerous times throughout the flight. When I stood up and tried to move through the cabin, I became very dizzy. After sleeping about 6 hours at home I felt a whole lot better. As to why I felt this way, I believe it was due to being assigned a transoceanic all-nighter turn after working another all-nighter. I was on reserve. I was assigned standby and then deadheaded to work the first all-nighter. I had a daytime layover and then worked back that night I was checking in for the next turn. I flew 22 hours which included 2 all-nighters. I was completely exhausted. I know that these trips are legal but our bodies (body clock) do not respond well to this type of assignment. It is very difficult to get the proper rest when sleeping during the day. I think we should either not be flying transoceanic all-nighter turns or consideration on our bodies need to be taken into account when assigning back-to-back trips. I was very concerned about my capability to evacuate the aircraft in an emergency and also of disarming my door on arrival. Not to mention the difficult time I had driving home. I felt that my exhaustion and dizziness affected my inflight performance and that I wasn't going to be able to react properly to a safety, medical, or security issue on the plane if one happened. Just because an assignment is legal on paper or might be acceptable during the day, special consideration needs to be taken into account when working all-nighters on a consecutive basis. Synopsis: Cabin attendant is concerned with fatigue due to multiple flights.

\section{4}

Narrative: Upon approach into ZZZ about '10' before preparation for landing I was picking up trash for the economy cabin and was nearing the first aft lavatory with the bags and papers in hand when severe turbulence hit. I was able to throw the trash in the lavatory (directly behind the last row of seats $\mathrm{ABC}$ ) but was thrown violently against the wall opposite the lavatory then back to the floor and subsequently back and forth against the armrests before I could properly grab hold of seat $35 \mathrm{C}$. I was in a fetal position and holding tightly as I could as the plane pitched back and forth, up and down. As the plane pitched and dropped the lower half of my body (twisting my 
spine) flopped up and down. I tried in vain to search for an empty seat/seatbelt and since the back jumpseats were taken, I took a real beating from the aircraft. A flight attendant was able to turn the corner to ask my condition and I was able to tell her that I was just able to hang on. Once there was a brief intermission from the severe turbulence I was able to run toward the mid jumpseat (door 2) to secure myself. We then had to hold approximately 1 hour before finding out that we had no more fuel to land in ZZZ and proceeded to ZZZ1. We landed and taxied to a remote part of the airport near a cargo hangar and held with no air whatsoever for about $31 / 2$ hours. We finally got an 'air start' after waiting for fuelers to be able to access us due to lightning then taxied to finally produce air. Several of the passenger as well as a flight attendant had to take oxygen due to lightheadedness. I also felt this but was able to have the cockpit open the windows for ventilation. We finally were cleared to go to $\mathrm{ZZZ}$ after the ground stop and being on the same aircraft for 8 hours 10 minutes according to ours (as well as the passenger calculations) they seemed to give us ' 1 minute' layover in ZZZ1 and tried to make us continue on to ZZZ2 two hours later. Fortunately, we were able to convince a scheduler of our legality but with definite resistance. Why is our company giving us a ' 1 minute' layover to make us legal for the next flight? To go illegal in the air?' the crew schedulers need to think about the safety and security of the passenger in these irregular situations and not about how much 'work' they will have to do in order to re-crew the flight. Not to mention I am extremely hurt and told them of my injuries. Synopsis: Cabin attendant injured when the B757-200 encounters severe turbulence and extended holding on arrival to ZZZ. Divert to ZZZ1 where they are unable to park and flight crew, cabin crew, and passenger remain on board until fueled at a remote location for the return flight to $\mathrm{ZZZ}$.

\section{7}

Narrative: During our flight to ZZZ the pilots received an automatics communications addressing $\&$ reporting system stating that, 1) flight attendants should contact scheduling when we arrive and, 2) that flight attendants will now work outbound flight ABCD back to ZZZ2. This would make our original 3-day trip into an overnight turn. The entire crew was exhausted and if we took the flight back to ZZZ2 we would have been up for over 24 hours. This is a safety issue. I contacted scheduling. He notified me that we were now being sent back to ZZZ2 because the crew was arriving late to ZZZ. I advised him of our situation and that we would not be able to work that flight. That we will be doing fatigue. Scheduling stated that we would have to report to the hospital if we intend on doing fatigue. I responded that it would not be a problem. Scheduling said that he would set it up and call me back. In the meantime, the outgoing pilots to ZZZ2 arrived and heard what was going on. Captain stated that he would not fly the plane back to ZZZ2 if we were working it. Short time later, airport paramedics and police arrived to the airplane. Paramedics wanted to know the situation. We explained what was happening. The lead paramedic stated that he could not treat us unless we were ill. He said that there was nothing he could do for us except give us a pillow and tell us to go to bed. He clearly stated that they do not get involved in employee relation issues. Scheduling said that the paramedics would take us to the hospital. The lead paramedic said he was not a taxi service. I contacted again and he said that he could go to plan B and call me back. Once again, he called me back and said that a van service would now take us to the hospital. We were sent to the hospital. We were admitted to the emergency room, after receiving funny looks from the emergency room staff. After falling asleep in our hospital beds, the doctor arrived. He asked what was wrong. I explained the situation to the doctor. He responded 'so you are not sick?' I said no, just tired and fatigued. He then responded, 'this is idiotic that your company sent you to the emergency room and wasted my time when I could be seeing patients that really need my attention.' we were released from the hospital to get rest in our hotel room. We continued to the hotel. We finally checked into the hotel. We deadheaded back to ZZZ2 on our original flight that we were supposed to work. Synopsis: An A319 flight attendant crew reports refusing to fly an unscheduled transcontinental return flight because of fatigue

\section{3}

Narrative: While setting up galley for flight, captain told us to stop, we were doing a plane change due to a mechanical. While setting up new galley, cleaning crew excitedly pulled me outside to see massive quantities of liquid pouring out of left wing. I ran forward yelling, 'captain look at the left wing...' no passenger onboard. Captain began yelling everyone get off the plane, get off (jetbridge still intact). We stood for some time watching jet fuel gush from left wing. Hazmat was called out to clean up and mechanics determined problem. As cleanup was going on, I had to go back into the airplane to get my jacket as it was very cold in the terminal. Smell was awful. After more time passed I had to go back onto airplane to get wallet so I could get some food from machine for myself and another flight attendant. Odor still very bad. Mechanics found two other problems with the aircraft, now going on a 3 hour delay. At some point captain asked us if we wanted to call fatigue and cancel flight. We all discussed it and all felt fine and really wanted to get these people to their destination. I could not stay on plane due to smell. I was in gate area most of time helping agents go from plane to plane looking for blankets for the people. Eventually, I hit the wall and felt ill. I had a sore throat and nauseous stomach. Called crew desk to tell them. They asked if I was calling fatigue. I said, 'I don't know what to tell you.' (I did not really understand what fatigue was). I told them I was sick and had to go to a hotel or home if I could get there. They said if I was calling fatigue I had to go to hospital now. I said I had to get to bed as soon as possible and would go to the hospital the next day. I made it home, slept for 7 or 8 hours then went to urgent care, got a shot of vitamin B. Dr said I had the beginnings of something but should be ok if I went back home to rest. Synopsis: After extended exposure, cabin attendant reports fumes from large fuel spill during fueling of her A320 which resulted in nausea and illness. As a result, reporter is unable to fly the trip and calls in sick.

\section{6}

Narrative: Due to fatigue, I failed to arm doors $1 \mathrm{~L}$ and $1 \mathrm{R}$ prior to takeoff. I realized once we were in the air that they weren't armed. My action was of course to immediately arm the doors. This is the second time due to fatigue I've had a door incident. I wrote a report a few months ago after doing a ZZZ1 turn where I nearly opened an armed door. How are the ZZZ1 turns legal, without a crew rest break? Anyway, since last month was my vacation month and we are now paid so little for 
vacation, I was forced to fly 115 hours in November to make up for it. We are being pushed beyond our limits! In my entire career, prior to air carrier's gouging of safety regulations and pay, post 911, I never came close to an incident. I feel that with the way the trips/duty days and minimum rests are it's only a matter of time. I also would like to say, that for every reported incident, there are at least 2 or 3 that go unreported! I hope that there is someone who reads this who actually cares, because the supposed leaders at our company do not give that impression. Synopsis: Cabin attendant reports failure to arm doors prior to takeoff. Cites fatigue stemming from long duty days and the reduction and elimination of on duty restrictions and extra work necessary to make up for pay cuts by the airline.

\section{5}

Narrative: The 2 day/all nighter Hawaii turns are completely unsafe. I was given this trip on reserve, and was beyond exhausted. As if the day Hawaii turns were bad enough, this adds additional insult to a duty period. On the return flight I was falling asleep, making careless actions (such as difficulty in closing the B757 cockpit barrier -- a task which is easy when fully rested, my hands were trembling when holding a coffee cup/saucer, I nearly forgot to disarm my door, I could barely think straight when making preparation for landing and welcome announcements). These are all simple actions which under normal well rested circumstances would never be compromised. The duty day is that of an international trip, however without a rest break. It is simply not human to work these hours during the night, and the fatigue we are submitted to is an enormous risk to the crew and passenger's safety. In addition to feeling unsafe in the workplace, it was completely unsafe driving home. I was nodding off behind the wheel, and experiencing great difficulty keeping my eyes open. My vision was blurry, and I was frightened for my safety. Air carrier is putting us at great risk on many levels. These Hawaii all nighter turns (as well as day turns) need to be reevaluated. They may 'look good on paper,' but the safety and fatigue related risks are too great. Pilots cannot fly them -- so why should we? Synopsis: B757 cabin attendant concerned with length of flight and fatigue issues.

\section{7}

Narrative: What happened: going from ZZZ to ZZZ1 and then back on the all-nighter is not safe. As I sat in my jumpseat upon landing, I had a very hard time keeping my eyes open. After landing and disembarking the plane, I could not even remember if I disarmed my door. I went back to do a double check and it was disarmed. Thank goodness I did not have to drive when we landed. I probably would have fallen asleep at the wheel. I am glad there was not a medical emergency. I don't feel I would have been able to handle it at $100 \%$. Why: Due to fatigue. What action was taken: I wrote this report. What was the outcome: Hopefully this type of trip will become illegal. It really is not safe. It would not be so bad, but the 2 hour sit while in ZZZ1 is the killer. Also if you are on reserve and cannot plan accordingly for this type of trip it is even more unsafe. Synopsis: Flight attendant reports debilitating fatigue experienced during all night flight to $Z Z Z 1$ and return to $Z Z Z$.

\section{1}

Narrative: Company is scheduling its cabin crew members to work all night turns to the Hawaiian Islands from mid-afternoon to early am PST/PDT following day. These trips go against a flight attendant's body rhythms and in my opinion push the boundaries of a built-in safety cushion. Upon the return flight two of my colleagues displayed visible signs of fatigue as their eyes were severely blood-shot. Additionally, approximately 1.5 hours prior to our arrival in ZZZ I began to see wavy lines (blurred vision) as I was attempting to keep my eyes open. Company provides no crew rest on these all night Hawaii turns. The cockpit crew, due to FAA duty-time standards, do not have to endure flying an island turn. Because of safety of flight concerns they (the cockpit crew) work one leg (flight segment) to the islands and requires a layover. My personal feeling, from my experience, is that the scheduling of all night Hawaii turns from the west-coast push the parameters of an adequate safety cushion. Situational awareness is greatly diminished because of cabin crew member fatigue and I believe that reaction time is significantly compromised on the part of working flight attendants should an inflight medical emergency occur or events that would necessitate an evacuate or preparation for a water ditching. Synopsis: A flight attendant describes crew members showing fatigue during round trip assignments to the Hawaiian Islands.

\section{0}

Narrative: We were scheduled for an XA50 pick-up giving us less than 8 hours at the hotel. I did not get sufficient sleep after working all night and was very tired as were my flying partners and this was my 5 th consecutive day of flying. At XA45 the crew desk called to notify us of a 50 minute delay but I was already in uniform and could not go back to sleep. We worked the flight to DEN and upon arrival at the gate I looked out of the window and saw the agent bringing the jetbridge to door 1L. I made an announcement to disarm doors, then I disarmed door $1 \mathrm{~L}$ and cracked it. I then went to door $1 \mathrm{R}$ and disarmed and cracked that door. When I turned back to door $1 \mathrm{~L}$ the agent was opening it. He opened it a few inches and stopped because the slide pack was coming out of the door casing and the girt bar was engaged. The agent backed away from the door and I quickly disengaged it and notified the pilots. A mechanic came and removed the slide pack and opened the door. Everything happened very fast. Synopsis: Beset with fatigue due to long duty days and five consecutive days of flying, cabin attendant fails to disconnect slide girt bar on B737-300 prior to cracking door to signify it was safe to be opened.

753781

Narrative: We arrived late into our rest period due to operational difficulties. We were scheduled for a 9 hour 53 minute rest period, reducible to 9 hours. When we reached our scheduling dept via phone, we were told we would be taken down to 8 hours and the pilots would be released after a round trip to ZZZ for crew rest. As flight attendant, I was told I would complete the entire trip, which was scheduled for 11 hours and 53 minutes of duty time and 7 hours and 45 minutes of flight time. I informed scheduling that I would also be fatigued and would like to be released after the ZZZ trip, but was told I had no time limits. I repeated that I would be too fatigued to fly nearly 8 hours and a nearly 12 hour duty day on $51 / 2$ hour sleep. I was told that if I was refusing to complete the trip, I would be charged with an 'occurrence' which is a step in the disciplinary process, and have my pay reduced for that trip. I elected to complete the trip, under these threats, but 
experienced considerable fatigue including, but not limited to, lack of concentration, short term memory difficulty, and speech problems. I feel I was forced to act as a crew member under duress while fatigued created a dangerous situation. This is a common practice with our crew scheduling dept and should be addressed. Synopsis: Cabin attendant is threatened with disciplinary action for requesting removal from a flight sequence after a layover shortened due to operational problems.

\section{4}

Narrative: I was working in the back. I had just disarmed my door at $2 \mathrm{R}$ at the back of the airbus. I was gathering my belongings when the phone rang from the front. The purser told me that she had accidentally deployed a slide at $1 \mathrm{~L}$ because she pulled the open handle thinking it was the disarm lever. We had just worked the all-nighter to ZZZ. Synopsis: Cabin attendant deploys escape slide vice disarming it upon arrival following all night flight.

\section{7}

Narrative: When crew boarded the entire aircraft was warm but the back of the aircraft was over 90 degrees and the bunk room was 109 degrees. The day was in the mid 70's but the aircraft sits in the hot sun on the remote with no cooling for hours. None of the window shades had been shut or the vents opened for cooling of the aircraft. This flight departs at XA45. Hot aircraft have been a consistent issue in ZZZ. A hot aircraft defeats everything that I do as a flight attendant to combat fatigue. My body is using up all its reserve fuel to keep my body cool thus the effects of fatigue hit early. This is a $131 / 2$ hour duty day and starting it off with a hot aircraft is unsafe and unhealthy. Aircraft at door 5 stayed at 90 degrees for over an hour into the flight. Again there were 3 breaks on this flight and although it was a day flight the hot aircraft that we boarded along with the turbulence that we encountered during all 3 breaks hindered the ability for crew to get sufficient rest. Without sufficient rest the crew is put at risk for fatigue. After this trip I took a 5 hour nap at home and still was able to sleep through the entire night. I have never slept that much after a trip and contributed it to the lack of rest created by 3 breaks and the hot cabin. Synopsis: Hot cabin, turbulence and ineffective cabin attendant rest schedule result in fatigue.

\section{7}

Narrative: Crew called in fatigue prior to show time because of insufficient rest. Company threatened termination of cabin crew if they did not operate. Cabin crew felt they were unsafe for flight operation, but operated out of fear of job termination by upper management. If emergency would have arisen, crew not sure they could have responded, could not stay awake to monitor cabin during flight. Asleep on jumpseat during flight and upon taxi out and landing. Synopsis: A B757-200 flight attendant was forced under threat of termination to fly a long two-legged flight after refusing to fly fatigued because of insufficient rest after previous flight.

\section{0}

Narrative: We were scheduled to work flight XX from ZZZ to ZZZ1 then layover for over 28 hours. We were drafted to work flight XY directly back from ZZZ1 to ZZZ2 as soon as we were able to deplane our passenger. We had absolutely no rest break at any time during the 11 hours 12 minutes of actual flight time or the 13 hours 22 minutes of duty time as we immediately began boarding the new flight. Our total flight time for that duty day went from scheduled 606 to 1112 . All three of us were unprepared to work so long. We had not taken naps or slept in late. If we had an emergency situation we would not have been at out best. I believe it was an unsafe situation and one that could have been prevented. Supplemental info from ACN 763301: Not having planned for this kind of 'turn' (getting proper rest before a trip and also expecting to go on a layover) resulted in exhaustion and not feeling that I would be able to execute my safety responsibilities clear headed if necessary. With the hours involved here and over 11 hours of flight time without a moment's rest seemed to surpass safety at all costs. Callback conversation with reporter ACN 763300 revealed the following info: the reporter stated that the second flight to which she was assigned had diverted earlier and when it finally reached its destination 3 of the 5 flight attendants were illegal to proceed on the return flight. Since the reporter's crew was legal the air carrier ordered 3 of them to join the other crew on its trip. The reporter was not prepared for such a long duty day: did not rest prior to check in, was not given a rest period on the first flight, and would not be given a rest on the next flight. Both aircraft in this event were full B757-200's. Synopsis: A flight attendant reports a schedule change after arrival at their RON destination required an immediate departure and a total duty day of $13+22$ hours with no break.

\section{2}

Narrative: I was the purser and after reaching the gate I announced for the flight attendants to disarm their doors and simultaneously turned on the cabin lights. I stared at my door. I think I looked at it 3 times and just as customer service approached to knock on the window, I realized the door was still armed! I quickly disarmed it and stood there shaking as I realized what could have happened! I had taken first break, which I normally don't do. By the end of third break I didn't feel very alert at all. In fact I could barely keep my eyes open. This amount of fatigue is scary and this was a real eye opener. Supplemental info from ACN 763298: Air carrier's directive of requiring 3 crew rest breaks on an all night non stop flight of such long duration is creating an unsafe work environment for both working crews and our passenger. Our entire crew was exhausted on arrival in ZZZZ and in the event of an emergency I dare say would not and could not have responded as quickly as we have been trained to do due to extreme fatigue. I personally was so overtired due to a short crew rest break and having been in first break that I felt dizzy and almost delirious. I had to check, double check, and triple check that my door was disarmed and that my flying partner's door was disarmed. Two of us had to perform post flight safety to be certain all doors were disarmed, lavatories unoccupied and opened and that all passenger were off the aircraft. Upon arrival at the hotel I was also so overtired I was unable to sleep, even though that's all I wanted and needed to do. I have flown this trip for years and I have never felt this physically exhausted. I had napped during the day of the trip and felt fine at briefing. Furthermore, in our flight attendant operation manual the paragraph following the break directive is a flight attendant coverage ratio. Doing two breaks from ZZZ to ZZZZ exceeds that coverage ratio. We do our best to make our passenger have an enjoyable flight but more importantly we need to ensure a safe flight staffed by alert and ready for any situation flight attendants. Situational 
awareness is an important part of our jobs, these days one of the most important parts of our jobs. Supplemental info from ACN 763327: Passenger reported to flight attendants upon deplaning that a female passenger had fallen and needed assistance. Flight attendants quickly provided oxygen, emotional support and a ready AED. Ground staff called for emergency medical professionals from the front door as the cockpit crew had already left the cockpit. My question is: Should air carrier discipline flight attendants for taking two rest breaks instead of three rest breaks given that we are first responders for all medical emergencies while on duty? Flight time is 14.5 hours. Callback conversation with reporter 763298 revealed the following info: Reporter stated that the current air carrier rest policy being enforced is 33.25 hours breaks. The flight attendants were scheduling their own breaks at a 24.5 hour break rotation but the air carrier is demanding the three shorter breaks for passenger service reasons. The flight is essentially all night so many people are asleep anyway. Fifteen flight attendants are now a normal crew complement for a 17.5 hour duty day that starts at night and ends at night. The cumulative fatigue leaves all crew members feeling ineffectual at the flight's termination. Adding a problem to the mix, such as a passenger medical emergency in this case, makes the situation even worse. Synopsis: Flight attendants question an air carrier's inflight rest policy requiring 3 short breaks vs. 2 longer breaks on long flights. The crew feels more rested and safe with 2 breaks.
763303

Narrative: Augmented staffing for entire trip required 6 flight attendants due to long duty time. Purser on the flight advised crew scheduler that only 5 flight attendants were on board for the trip and that we were not legally staffed according to the flight manual. After a lengthy discussion with the purser other flight attendants and scheduler, we were advised by the scheduler that we would have to work the flight with 5 flight attendants. The scheduler was asked if she was giving us a direct order. She said yes and so we advised her that we would work under protest and that we were understaffed according to the flight manual. We did not have access to a computer at the time but upon return from the trip I pulled up requirements and the print up under comments stated 'augmented staffing required: flight XX needs: 6 flight attendants.' Synopsis: A flight attendant reports the air carrier forced the flight attendant crew to depart one flight attendant short of the required number on a long duty time flight. 